\title{
Artificial Shading Can Adversely Affect Heat-tolerant Lettuce Growth and Taste, with Concomitant Changes in Gene Expression
}

\author{
Camila M.L. Alves, Hsueh-Yuan Chang, and Cindy B.S. Tong \\ Department of Horticultural Science, University of Minnesota, St. Paul, MN 55108 \\ Charlie L. Rohwer \\ Southern Research and Outreach Center, University of Minnesota, Waseca, MN 56093 \\ Loren Avalos and Zata M. Vickers \\ Department of Food Science and Nutrition, University of Minnesota, St. Paul, MN 55108
}

\begin{abstract}
ADDITIONAL INDEX wORDs. bitterness, chlorophyll, Lactuca sativa, quality, sweetness, transcriptome
Abstract. Shading has been used to produce high-quality lettuce (Lactuca sativa) in locations where production conditions are not optimal for this cool-season crop. To learn what additional benefits shading provides if heat-tolerant cultivars are used and to understand the effects of shading on growth, sensory quality, chemical content, and transcriptome profile on heat-tolerant lettuce, we grew two romaine lettuce cultivars with and without shading using 50\% black shadecloth in 2018 and 2019. Shading reduced plant leaf temperatures, lettuce head fresh weights, glucose and total sugars content, and sweetness, but not bitterness, whereas it increased lettuce chlorophyll b content compared with unshaded controls. Transcriptome analyses identified genes predominantly involved in chlorophyll biosynthesis, photosynthesis, and carbohydrate metabolism as upregulated in unshaded controls compared with shaded treatments. For the tested cultivars, which were bred to withstand high growing temperatures, it may be preferable to grow them under unshaded conditions to avoid increased infrastructure costs and obtain lettuce deemed sweeter than if shaded.
\end{abstract}

Lettuce (Lactuca sativa) is an important cool-season vegetable crop species, with more than 2 million tonnes produced in the United States in 2019 [U.S. Department of Agriculture (USDA), National Agricultural Statistics Service, 2020]. The ideal average daily temperature for field-grown lettuce is $18.5^{\circ} \mathrm{C}$, and high temperatures may negatively affect lettuce growth and development leading to tipburn, undesirable bitterness, and early bolting due to a reduced growing period (Waycott and Ryder, 1993). Bitterness, an important taste characteristic of lettuce usually associated with consumer rejection (Drewnowski and Gomez-Carneros, 2000), has been found to increase with higher growing season temperatures (Simonne et al., 2002).

Bunning et al. (2010) found that genotypic differences had a greater effect than environmental conditions on sensory and phenolic content of lettuces. Sensory analyses of lettuce have demonstrated genotypic differences (Simonne et al., 2002; Zhao and

Received for publication 20 Aug. 2021. Accepted for publication 14 Oct. 2021.

Published online 9 December 2021

We thank Aaron Blythe for input on research design; Doug Brinkmann, Courtney Tchida, Adam Sauve, Jessyca Martínez-Vélez, and Taylor Bushelle for technical assistance; Juan E.A. Llorens for assistance with transcriptome analysis; Gary Oehlert for statistical consultation; and Dominic Petrella and Yinjie Qiu for reviewing drafts of this manuscript. Funding was provided by the U.S. Department of Agriculture (USDA) Marketing Service (grant 64436 via the Minnesota Department of Agriculture Specialty Crops Block Grant Program) and the Minnesota Experiment Station (projects MN21-043 and 18-138). The contents of this manuscript are solely the responsibility of the authors and do not necessarily represent the official views of USDA.

C.B.S.T. is the corresponding author. E-mail: c-tong@umn.edu.

This is an open access article distributed under the CC BY-NC-ND license (https://creativecommons.org/licenses/by-nc-nd/4.0/).
Carey, 2009), especially in bitterness, which may be attributed to differing quantities of bitter components, including sesquiterpene lactones, lactucin, and lactucopricrin (Price et al., 1990). Bitterness perception may be counteracted by sweetness, with the ratio of bitter-to-sweet compounds determining bitterness perception and liking (Chadwick et al., 2016). Breeding efforts may lead to new cultivars that are more heat tolerant and less bitter, but the development of new cultivars can be expensive and time-consuming (Driedonks et al., 2016).

In addition to the development of heat-tolerant cultivars, technologies that alter light intensity and temperature can be used to improve growth and productivity of crops under high temperature conditions. Several research groups have studied the effects of shading on lettuce growth, yield, bitterness, and chemical composition. The use of $39 \%$ white shadecloth over high tunnels reduced lettuce leaf surface temperature by 1.5 to $2.5^{\circ} \mathrm{C}$, as well as head weights of loose-leaf and butterhead, but not romaine, lettuces compared with lettuce grown in the open field (Zhao and Carey, 2009). In contrast, lettuce grown in the field under $50 \%$ black shade had greater marketable head weight and diameter, and chlorophyll and carotene content, than unshaded controls (Ilić and Fallik, 2017, Ilić et al., 2017). Mastilović et al. (2019) observed that shaded lettuce had lower soluble solids content, which is linked to sweetness, than those grown in the open field. Because consumers have a preference for sweeter lettuce (Chadwick et al., 2016), open field-grown lettuce may be preferable to shaded lettuce.

To produce lettuce under high temperatures, the use of both well-adapted cultivars and suitable production technologies are needed to provide effective solutions to these problems. Growers may first choose to raise heat-adapted cultivars before adopting 
shading technology, due to the increased costs and labor in using shade technology. The objective of this study was to evaluate whether shading technology would improve production and consumer appeal of heat-tolerant lettuce cultivars under high temperature growing conditions. In this study we evaluated lettuce growth, sensory properties, chemical content, and transcriptomic differences of heat-tolerant lettuces grown under $50 \%$ black shadecloth or unshaded field conditions.

\section{Methods}

Plant materials and Growing conditions. 'Salvius' and 'Sparx' romaine lettuce were grown from seed (Johnny's Selected Seeds, Winslow, ME). These cultivars have been reported to be heat-tolerant (Holmes et al., 2019) and were chosen at the recommendation of Minnesota growers. Seeds were sown in organic growing media. In 2018, the growing media that was used was Sunshine (Sun Gro Horticulture, Agawam, MA) or Seed Starter Mix (Purple Cow Organics, Middleton, WI). In 2019, the growing media consisted of Pro-Mix Mycorrhizae Organik (Premier Horticulture, Victor, NY) mixed with 7N-2.2P-8.3K organic fertilizer (BioWorks Verdanta EcoVita; BFG Supply Co., St. Paul, MN). All seedlings were grown in a greenhouse set at $21^{\circ} \mathrm{C}$ day/night on a mist bench for 4 to 6 weeks, and then hardened off in an outdoor coldframe until transplanted in the field.

Field EXPERIMENTAL DESign AND TREATMENTS. Experiments were replicated over 2 years at two locations (both USDA Plant Hardiness Zone 4b) on the St. Paul campus of the University of Minnesota (lat. $44.9740^{\circ} \mathrm{N}$, long. $93.2277^{\circ} \mathrm{W}$; Waukegan silt loam) and at the Southern Research and Outreach Center (SROC) in Waseca, MN (lat. $44.0707^{\circ} \mathrm{N}$, long. $93.5264^{\circ} \mathrm{W}$; Webster clay loam). Both field locations fall within Koppen climate zone Dfa (hot-summer humid continental).

Fertilizer was applied at rates based on soil test results and previous crop histories. In St. Paul, urea was applied to plots in 2018, but 8N-0.9P-3.3K organic fertilizer (Sustane Natural Fertilizer, Cannon Falls, MN) was used in 2019. At the SROC, lettuce plots received $5 \mathrm{~N}-1.3 \mathrm{P}-2.1 \mathrm{~K}$ and $3 \mathrm{~N}-3.1 \mathrm{P}-3.3 \mathrm{~K}$ organic fertilizers [Chickity Doo (Pearl Valley Organix, Pearl City, IL) and Sustane Natural Fertilizer, respectively] in 2018. In 2019, the fertilizer used at the SROC was $5 \mathrm{~N}-1.3 \mathrm{P}-2.1 \mathrm{~K}$ organic fertilizer (Sustane Natural Fertilizer) with the addition of $0 \mathrm{~N}-20.1 \mathrm{P}-0 \mathrm{~K}$ triple superphosphate (Ag Partners, Morristown, $\mathrm{MN}), 0 \mathrm{~N}-0 \mathrm{~N}-49.8 \mathrm{~K}$ potassium chloride, $44 \mathrm{~N}-0 \mathrm{P}-0 \mathrm{~K}$ slowrelease urea (Jordan Seeds, Woodbury, MN), and $46 \mathrm{~N}-0 \mathrm{~N}-0 \mathrm{~N}$ urea (Ag Partners). Raised beds $(0.1 \mathrm{~m}$ high at the SROC or $0.3 \mathrm{~m}$ high in St. Paul $\times 1$ to $1.5 \mathrm{~m}$ wide) were made and covered with white on black embossed plastic mulch (Ag Resource, Detroit Lakes, MN) and equipped with 0.38-mm low flow drip irrigation (Aqua-Traxx; DripWorks, Willits, CA), used as needed based on weather conditions. Transplants were planted $30 \mathrm{~cm}$ apart in single rows.

A split-plot design was used for field experiments in 2018 and 2019. Blocks $(15.24 \mathrm{~m}$ long $\times 1.5 \mathrm{~m}$ wide) were split into shaded or unshaded (control) plots ( $6 \mathrm{~m}$ long $\times 1.5 \mathrm{~m}$ wide). Cultivars were randomized into one of two subplots within each shade treatment. There were four replicate blocks at each location per year, with two whole plots (shade or no shade) per block and two subplots ('Salvius' or 'Sparx') per whole plot. Treatments consisted of shading with netting that was designed to reduce photosynthetically active radiation by $50 \%(50 \%$ Pull and Cut Sunblocker; FarmTek, Dyersville, IA) attached to 1.5-m-tall hoops made from bent electrical conduit, and unshaded control treatments not covered by hoops or shading.

Lettuce plants were transplanted in four randomized blocks in each location on 1 June 2018 and 30 May 2019 at the SROC and 12 June 2018 and 26 May 2019 in St. Paul under each treatment. This was done to ensure that lettuce was grown under high temperatures. There were 19 plants staggered within each subplot. Lettuce was harvested at the SROC on 11 July 2018 and 15 July 2019 and in St. Paul on 16 July 2018 and 15 July 2019. All lettuce was harvested before bolting.

Field Measurements. Weather stations at both locations recorded daily temperature and precipitation data. In 2018, plant leaf temperatures were measured using handheld infrared (IR) thermometers pointed at leaf surfaces. In 2019, microtemperature sensors were clipped onto adaxial leaf surfaces (unshaded by other leaves) about halfway between the core and outer leaves on a leaf of one plant per treatment per row, and data were recorded with data loggers (WatchDog; Spectrum Technologies, Aurora, IL). There were no differences between temperature measurements made using the handheld IR thermometer (mean of five measurements $=24.9 \pm 1.3^{\circ} \mathrm{C}$ ) and the micro sensor $\left(23.2 \pm 1.7^{\circ} \mathrm{C}\right)$. Photon flux density measurements were made at solar noon on 19 July 2021 using a field spectroradiometer (SS110; Apogee Instruments, Logan, UT) equipped with a $180^{\circ}$ field of view head placed $0.5 \mathrm{~m}$ aboveground surface. Three measurements were made for each treatment - under the shadecloth and without the shadecloth.

Sensory Evaluations. The University of Minnesota Institutional Review Board approved all recruiting and experimental procedures of all sensory tests. All tasters were 6-n-propylthiouracil tasters or supertasters, so have the ability to taste bitterness (supertasters are particularly sensitive) and were compensated for the testing session.

Sensory evaluations of lettuce were performed by 12 trained panelists in 2019 at the Sensory Center at the University of Minnesota. Two different sensory studies were done. The objective of the first study was to measure the intensity differences in sweetness and bitterness across two lettuce cultivars (Salvius and Sparx), under two shading treatments (shaded and unshaded), at two locations (St. Paul and the SROC). Three lettuce heads of each cultivar and treatment were harvested from each block at the two test locations the day before testing and stored at $0{ }^{\circ} \mathrm{C}$ until transported the next day to the Sensory Center. Outer leaves of each head of lettuce were removed at the time of harvest. All lettuce was harvested before bolting.

All samples used for sensory evaluations were prepared from the middle leaves. On the day of testing, 12 to 13 leaves were removed from each head of lettuce and washed thoroughly with cold tap water. The leaves were laid out on absorbent mats (up\&up $^{\text {TM}}$, Target Corp., Minneapolis, MN) labeled with each sample's three-digit blinding code. Lettuces were examined for damage caused by insects or bacteria and patted dry with cloth dish towels. Leaves with no visible damage were portioned into 6-cm sections from the middle of the leaf and cut in half lengthwise to include both rib and leafy material. Lettuces with pest or abiotic damage were portioned to avoid the damaged section. If unable to get 12 portions from 12 separate leaves, two portions were taken from one larger undamaged leaf. Lettuce samples were presented to participants in sets of eight, with each set 
including one replicate of the two shadings by two cultivars by two locations in snack size zip-top bags (up\&up ${ }^{\mathrm{TM}}$ ) coded with a random three-digit number. These bagged leaves were refrigerated until $30 \mathrm{~min}$ before serving, then allowed to equilibrate to room temperature.

Sixteen samples, replicates 1 and 2, were served on the first day (16 July 2019), and 16 samples, replicates 3 and 4, were served on the second day (17 July 2019). Panelists always tested replicate 1 before replicate 2 , and replicate 3 before replicate 4 . This was done to ensure that the same samples were not randomly served multiple times in a row and to expose panelists to the entire range of samples as early as possible. Samples within each replicate were served balanced for order and carryover effects using Williams Latin square designs. For the entirety of testing, panelists were instructed to use nose clips to ensure evaluation of basic tastes only. Panelists started each testing session with a set of two citric acid calibration solutions with immediate feedback. Panelists were instructed to use the citric acid scale intensity reference samples (Karalus et al., 2010) provided as needed. During the testing session, each panelist rated each sample for the intensity of sweetness and the intensity of bitterness. Panelists were instructed to "remove the entire piece of lettuce from your bag. Roll the lettuce and put the whole piece into your mouth at once. Chew the sample thoroughly and swallow before making your evaluations." These attribute ratings were made on a 20-point line scale labeled none at the left end and intense at the right end. Panelists were provided with room-temperature filtered water to rinse their mouths between samples.

Weight AND CHEMical MEASUREMENTS. Six heads of lettuce were sampled from each subplot within a block, and fresh weights were measured in the field immediately after harvest in both 2018 and 2019. All lettuce was harvested before bolting.

Lettuce leaf soluble sugars, chlorophyll, and carotenoid levels were measured only in 2019. Middle leaves from one head of each cultivar and treatment from each of four blocks of both growing locations were assayed. For soluble sugar analyses, $\approx 0.5 \mathrm{mg}$ of finely sliced fresh leaf material was placed into $2-\mathrm{mL}$ screwcap tubes with $1 \mathrm{~mL}$ of $80 \%(\mathrm{v} / \mathrm{v})$ ethanol and incubated in a water bath at $80^{\circ} \mathrm{C}$ for $4 \mathrm{~h}$. After this time, supernatants were transferred to new 2-mL screwcap tubes. The plant material was washed with $0.5 \mathrm{~mL} 80 \%(\mathrm{v} / \mathrm{v})$ ethanol and the supernatants were combined, and then completely dried using a concentrator (Savant SpeedVac model SVC-100H; Thermo Fisher Scientific, Waltham, MA) connected to a refrigerated vapor trap (Savant model RVT400, Thermo Fisher Scientific). The dried materials were dissolved in $100 \mu \mathrm{L}$ of deionized water. Sucrose, fructose and glucose contents were determined enzymatically using a sugar analysis kit (K-SUFRG; Megazyme, Wicklow, Ireland) according to manufacturer instructions.

Chlorophyll levels were determined according to Han et al. (2016). Approximately $0.5 \mathrm{~g}$ of fresh leaf tissue was finely sliced and transferred into $50-\mathrm{mL}$ tubes to which $10 \mathrm{~mL}$ of $95 \%(\mathrm{v} / \mathrm{v})$ ethanol was added. Tubes were covered with aluminum foil, and chlorophyll was extracted at room temperature for $24 \mathrm{~h}$. Aliquots $(210 \mu \mathrm{L})$ were measured at $649 \mathrm{~nm}\left(\mathrm{~A}_{649}\right), 664 \mathrm{~nm}\left(\mathrm{~A}_{664}\right)$, and $470 \mathrm{~nm}\left(\mathrm{~A}_{470}\right)$ using a spectrophotometer (SpectraMax 190; Molecular Devices, San Jose, CA) equipped with data analysis software (SoftMaxPro 5.2, Molecular Devices). Chlorophyll a, chlorophyll b, and carotenoid concentrations were calculated using the following equations (Sumanta et al., 2014):

$$
\text { Chlorophyll } \mathrm{a}=13.36 \mathrm{~A}_{664}-5.19 \mathrm{~A}_{649}
$$

$$
\begin{aligned}
& \text { Chlorophyll } \mathrm{b}=27.43 \mathrm{~A}_{649}-8.12 \mathrm{~A}_{664} \\
& \text { Carotenoids }=\left(1000 \mathrm{~A}_{470}-2.13\right. \text { Chlorophyll a } \\
&-97.63 \text { Chlorophyll } \mathrm{b}) / 209
\end{aligned}
$$

RNA EXTRACTION AND SEQUENCING. One leaf was collected from each of four heads of 'Sparx' lettuce per treatment after sensory evaluation sampling in 2019 and pooled together for RNA analyses. Two biological replicates (biologically distinct samples) from each treatment (unshaded and shaded) were subjected to sequencing. RNA extraction was performed using an RNA extraction kit (RNeasy mini kit; Qiagen, Valencia, CA). RNA concentration was measured with a spectrophotometer (NanoDrop, Thermo Fisher Scientific) and tested for integrity using electrophoretic separation (RNA ScreenTape System, Agilent Technologies, Santa Clara, CA). RNAs with RNA Integrity Number $\geq 7.0$ were selected for library preparation. cDNA libraries were constructed by the University of Minnesota Genomics Center using the Illumina TruSeq RNA sample preparation protocol stranded with ribosomal reduction. The libraries were sequenced on a sequencing system (Illumina HiSeq 2500 using the NextSeq Mid-Output platform; Illumina, San Diego, CA) to generate 150-bp paired-end sequence reads. Quality control of the sequence reads was performed using FastQC version 0.11.9 software (Andrews, 2010). Low-quality reads (Phred score $<30$ ) and adapter contamination were removed using the Trimmomatic software tool (Bolger et al., 2014). The trimmed reads were mapped to the L. sativa cv. Salinas reference genome (Reyes-Chin-Wo et al., 2017) using HISAT2 software (Kim et al., 2019) with default settings. The number of reads aligned to each gene was counted using the featureCounts program from the Subread package (Liao et al., 2019).

Transcriptome analyses. Differentially expressed genes (DEGs) between unshaded control and shaded lettuce were identified using the Bioconductor edgeR software package (Robinson et al., 2010). False discovery rate $(F D R)<0.05$ and $\mid \log _{2}$ (foldchange) $\mid>2.0$ were set as the thresholds for differential expression. Analyses to describe DEGs according to Gene Ontology project (GO) descriptors were performed using the Bioconductor goseq $\mathrm{R}$ software package (Young et al., 2010), and Kyoto Encyclopedia of Genes and Genomes (KEGG) pathway analyses were conducted using the enrichKEGG function of the ClusterProfiler $\mathrm{R}$ package (Yu et al., 2012). Enriched GO terms and KEGG pathways were determined at FDR $<0.05$. Gene annotations were obtained from the National Center for Biotechnology Information database.

Quantitative reverse transcriptase polymerase chain reaction (qRT-PCR) methodology was used to validate transcriptome analyses (i.e., confirm RNA sequencing results) because only two biological replicates had been used for RNA sequencing (RNAseq). qRT-PCR was done using a SYBR green reagent system (CFX96 Touch Real-Time PCR Detection System; BioRad, Hercules, CA). First strand cDNA was synthesized with a reverse transcriptase kit (GoScript; Promega Corp., Madison, WI) in two steps. The first step consisted of adding $4.0 \mu \mathrm{L}$ of RNA (1200 ng), $0.7 \mu \mathrm{L}$ of oligo $\mathrm{dt}_{15}$ primer and $0.3 \mu \mathrm{L}$ random primers. The mixture was heated to $70^{\circ} \mathrm{C}$ for $5 \mathrm{~min}$ and then immediately chilled on ice for at least $5 \mathrm{~min}$. Five microliters of the reaction mixture were added to $4.0 \mu \mathrm{L} 5 \times$ reaction buffer, $2.0 \mu \mathrm{L} \mathrm{MgCl} 2,1.0 \mu \mathrm{L}$ PCR nucleotide mix, $0.5 \mu \mathrm{L}$ recombinant ribonuclease inhibitor, $1.0 \mu \mathrm{L}$ reverse transcriptase, and $6.5 \mu \mathrm{L}$ nuclease free water, in a final volume of $20 \mu \mathrm{L}$, incubated for $5 \mathrm{~min}$ at $25^{\circ} \mathrm{C}$, followed by $1 \mathrm{~h}$ at $42^{\circ} \mathrm{C}$, and finally inactivated 
for 15 min at $70^{\circ} \mathrm{C}$. cDNA was diluted $10 \times$ to be used for qRTPCR reactions. qRT-PCR was performed for 26 DEG genes, including 15 downregulated, 11 upregulated, and four housekeeping genes (Supplemental Table 1). Primer pairs were designed using Primer-BLAST software (Ye et al., 2012). Each $10-\mu \mathrm{L}$ qRT-PCR reaction contained a mixture of $2.0 \mu \mathrm{L}$ cDNA, 5.0 $\mu \mathrm{L}$ cyanine dye (SYBR Green, Bio-Rad) and $0.2-\mu \mathrm{L}$ pairs of primers $(400 \mathrm{nM}$ each). The thermal cycling conditions were initial denaturation for $5 \mathrm{~min}$ at $95^{\circ} \mathrm{C}, 40$ cycles at $95^{\circ} \mathrm{C}$ for $20 \mathrm{~s}$, $60^{\circ} \mathrm{C}$ for $30 \mathrm{~s}$, and $72^{\circ} \mathrm{C}$ for $30 \mathrm{~s}$. Melting curve analyses were performed at the end of qRT-PCR amplifications over the range of 65 to $95^{\circ} \mathrm{C}$, increasing temperature stepwise by $0.5^{\circ} \mathrm{C}$ every $5 \mathrm{~s}$. Gene expressions were normalized using tubulin beta- 2 chain-like as a reference gene. Relative gene expression was calculated using the $2^{-\Delta \Delta \mathrm{CT}}$ method (Livak and Schmittgen, 2001). Four biological replicates and two technical replicates (repeated measurements of each biological sample) were performed for each treatment.

Statistical analyses. Linear mixed effects models were performed using the lme4::nlme package (Bates et al., 2015) for $\mathrm{R}$ software (version 1.2.1335 or 4.1.1; RStudio, Boston, MA) to model treatment effects on lettuce fresh weight (measured in 2018 and 2019) and carotenoid, chlorophylls, fructose, glucose, sucrose, and total sugar content (measured in 2019). Dependent variable transformations were carried out as needed to meet analysis of variance (ANOVA) assumptions. Fresh weights and total sugars were square root transformed, and glucose and sucrose contents were logtransformed. Treatment, cultivar, and their interaction were included as fixed effects, while blocking [blocks, location, and year (fresh weight data)] and whole plot effects (year by location by block by treatment) were included as random effects.

To determine if sweetness or bitterness intensities differed by treatment, cultivar, location, or their interactions, ANOVA [PROC GLM (SAS version 9.4; SAS Institute, Cary, NC)] were used for sensory evaluations. Sweetness and bitterness were the dependent variables; treatment, cultivar, location, and replicate were fixed predictors; participant was a random predictor. All main effects, two-way interactions, and three-way interactions of treatment, cultivar, and location were present in the model.

To identify DEGs in lettuce grown with and without shade, the Bioconductor edgeR package (Robinson et al., 2010) was used. To designate changes in gene expression, FDR $<0.05$ and $\left|\log _{2} \mathrm{FC}\right|>2.0$ were set as the thresholds for differential expression. Correlations between results of qRT-PCR and RNAseq were analyzed using the Spearman coefficient.

\section{Results}

Field MEASuREMenTs. In 2018 and 2019, the St. Paul and the SROC sites experienced temperatures for lettuce production that were above the optimal $\left(18.5^{\circ} \mathrm{C}\right)$ listed by Zhao and Carey (2009). For the period of lettuce production, average maximum temperatures in St. Paul were 29.1 and $24.4{ }^{\circ} \mathrm{C}$ in 2018 and 2019 , respectively, whereas they were 27.3 and $25.8^{\circ} \mathrm{C}$ at the SROC in 2018 and 2019, respectively.

Lettuce leaf temperatures were unaffected by shading treatments in 2018 (data not shown), but temperatures were only measured at noon by handheld thermometers. In 2019, when thermistors connected to recorders were used to record leaf temperatures, the $50 \%$ shadecloth lowered plant maximum, but not minimum, temperatures (Fig. 1A and B). The maximum leaf

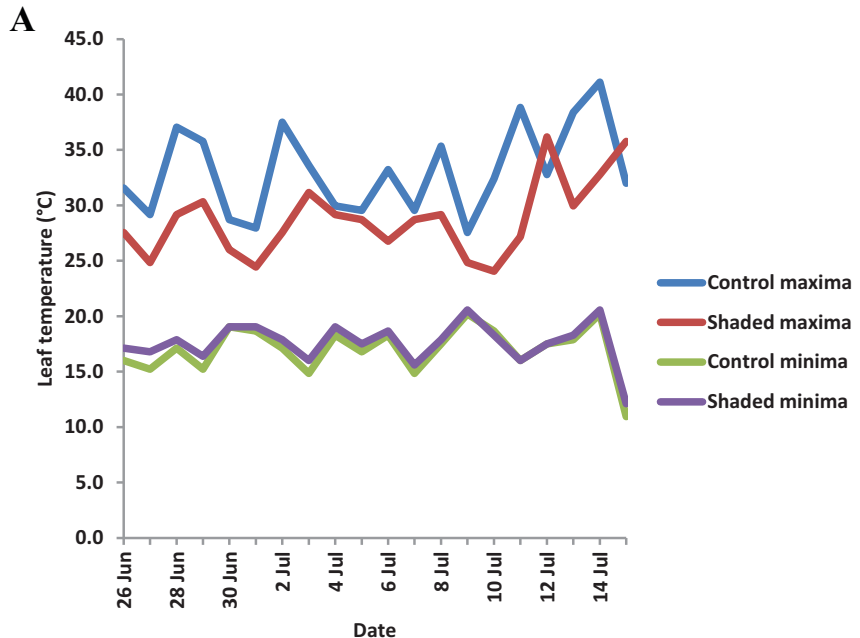

B

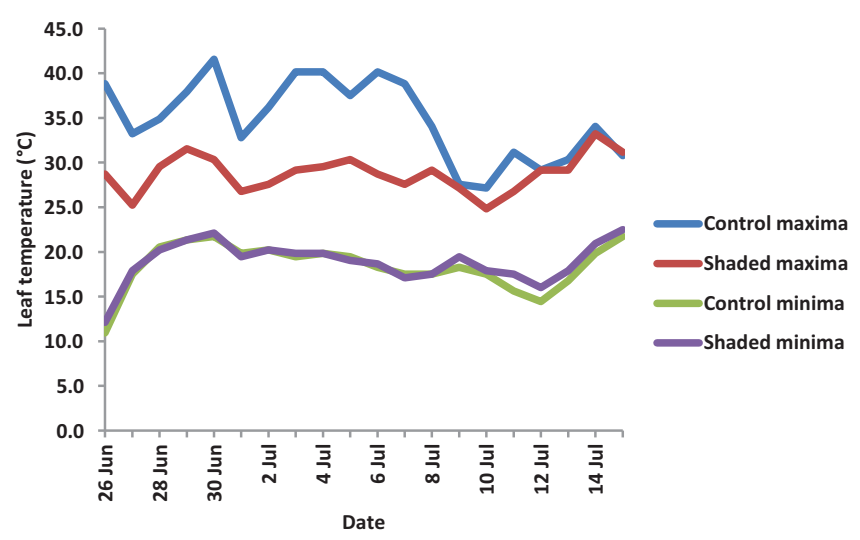

C

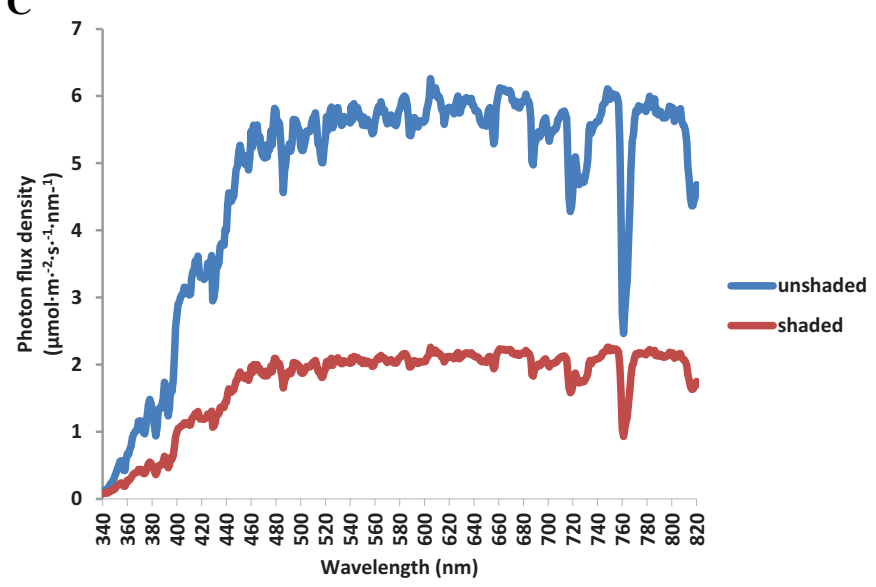

Fig. 1. Daily (month/day) surface leaf temperatures measured in 2019 using microtemperature sensors clipped onto adaxial leaf surfaces (unshaded by other leaves) about halfway between the core and outer leaves on a leaf of one plant per treatment per row of (A) lettuce under 50\% shadecloth (shaded) and control (unshaded) at St. Paul, MN, and (B) lettuce under 50\% shadecloth (shaded) and control (unshaded) at the Southern Research and Outreach Center in Waseca, MN. (C) Light spectra recorded with a field spectroradiometer on 19 July 2021 at solar noon without or with the shadecloth.

temperature reduction caused by shadecloth at St. Paul was observed when the leaf temperature was reduced from 38.8 to $27.2^{\circ} \mathrm{C}$ (Fig. 1A). At the SROC, the maximum leaf temperature reduction due to shadecloth was from 40.2 to $28.7^{\circ} \mathrm{C}$ (Fig. 1B). 
A

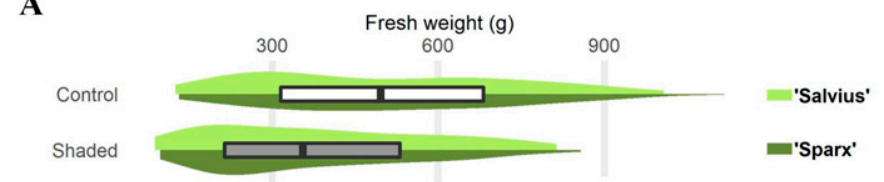

B
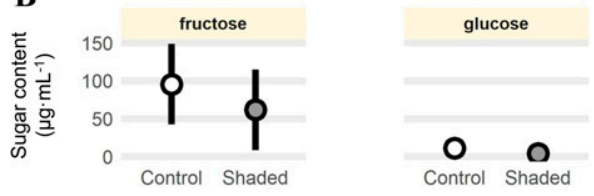

C

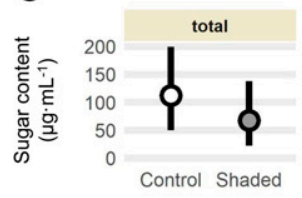

E
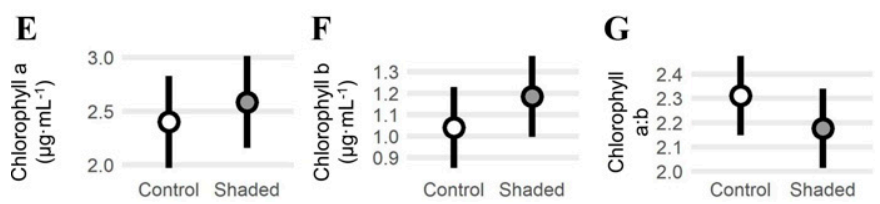

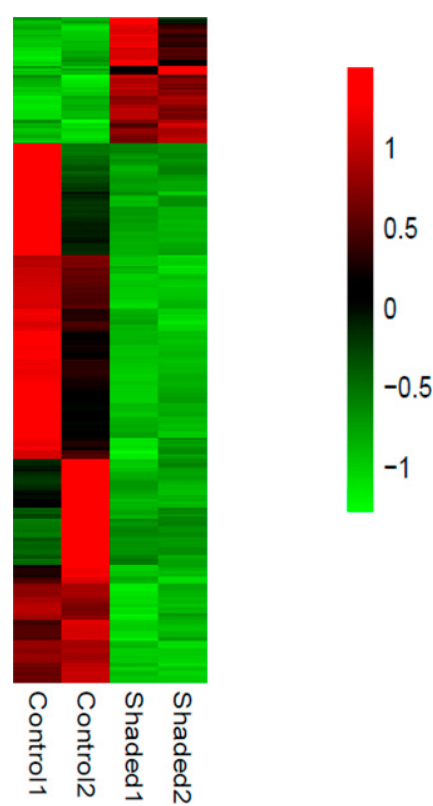

Fig. 2. Quality of 'Salvius' and 'Sparx' (pooled for location) lettuce produced under unshaded (control) or $50 \%$ black shadecloth conditions. (A) Head fresh weights pooled for 2018 and 2019, showing median and interquartile range, and distribution of raw data for each cultivar $(n=8$ per cultivar). (B and C) Marginal mean $\pm 95 \%$ confidence interval (CI) of fructose, glucose, sucrose, and total sugars in 2019. (D) Bootstrapped $(n=100,000)$ mean sweetness ratings $\pm 95 \%$ CI of lettuce harvested in 2019. Sweetness ratings were made on a 20 -point line scale, with $0=$ no sweetness and $20=$ intense sweetness, but all ratings were $<5$, so the graphed $y$-axis maximum $=4$. (E-G) Chlorophyll a and b and chlorophyll a-to-b ratio of 2019 lettuce (marginal means $\pm 95 \%$ confidence interval). CI bars that are not visible are obscured by the mean $(\mathrm{N}=16$ for means shown in $\mathbf{B}-\mathbf{G})$.

Average leaf temperature decreases for shaded lettuce compared with unshaded controls were 4.4 and $6.0^{\circ} \mathrm{C}$ in St. Paul and the SROC, respectively.

The photosynthetic photon flux density under the shadecloth ranged from 572 to $595 \mu \mathrm{mol} \cdot \mathrm{m}^{-2} \cdot \mathrm{s}^{-1} \cdot \mathrm{nm}^{-1}, \approx 35 \%$ of that of full sunlight, which ranged from 1591 to $1880 \mu \mathrm{mol} \cdot \mathrm{m}^{-2} \cdot \mathrm{s}^{-1} \cdot \mathrm{nm}^{-1}$. The spectral pattern was not changed by the shadecloth (Fig. 1C).

LeTtuCe QuaLiTy. Cultivar and location effects were not significant for lettuce fresh weight, sweetness, or sugar content. Fresh weight was the same in both 2018 and 2019. Shading reduced lettuce fresh weights of 'Salvius' and 'Sparx' $(P<$ 0.001) heads in both 2018 and 2019 (results shown in Fig. 2A aggregated across years and locations). The most abundant sugar found in lettuce was fructose (Fig. 2B). Total sugar and glucose content $(P=0.04$ and 0.02 , respectively), but not fructose $(P=$ $0.06)$ or sucrose $(P=0.07)$ contents, differed between unshaded and shaded lettuce. Mean total sugar and glucose contents were 128.7 and $15.3 \mu \mathrm{g} \cdot \mathrm{mL}^{-1}$, respectively, for unshaded control lettuce, and 79.4 and $8.1 \mu \mathrm{g} \cdot \mathrm{mL}^{-1}$ respectively, for shaded lettuce. Treatment $(P<0.001)$, cultivar $(P=0.02)$, and location $(P<$ $0.001)$ had significant effects, but none of the interactions of these factors significantly affected sweetness ratings of lettuce in 2019. Sensory evaluation participants rated unshaded lettuce as slightly sweeter (mean sweetness intensity of 2.9 ) than shaded
Fig. 3. Heatmap showing how many of the 313 genes identified from the RNA sequencing experiment as differentially expressed between unshaded control and shaded lettuce were upregulated (red) or downregulated (green) relative to the other treatment; 1 and 2 refer to the two biological replicates that were sequenced for the unshaded control or shaded treatments.

(mean sweetness intensity of 2.3) lettuce (Fig. 2D) and did not discern differences in bitterness based on shading treatment (data not shown). 'Sparx' was rated sweeter than 'Salvius', and lettuce grown at the SROC was rated sweeter than those grown in St. Paul (data not shown).

In 2019, shaded lettuce in our study had higher chlorophyll b $[P=0.02$ (Fig. 2F)], but not total chlorophyll $(P=0.11)$, chlorophyll a $[P=0.20$ (Fig. 2E)], or carotenoid $(P=0.34)$ content. The ratio of chlorophyll a to chlorophyll $b$ was greater in unshaded control lettuce $\left(2.31 \pm 0.08 \mu \mathrm{g} \cdot \mathrm{mL}^{-1}\right)$ than in shaded lettuce $\left(2.18 \pm 0.08 \mu \mathrm{g} \cdot \mathrm{mL}^{-1}\right)$, with $P=0.01$ (Fig. $2 \mathrm{G}$ ). Interactions of location or cultivar with treatment were not significant for chlorophyll $\mathrm{b}$ content or chlorophyll a-to-b ratio.

TransCriptome analyses. RNA sequencing generated 111 million paired-end 150 -bp reads, where $16.4 \%$ of the raw reads were removed after adaptor trimming and quality filtering, resulting in an average of 25 million reads per sample. The clean reads ratio was higher than $83.6 \%$. Genome mapping by HISAT2 successfully aligned 20.5 to 28.7 million reads to the lettuce genome. Using $\log _{2}$-fold change $\geq 2$ and FDR $<0.05$ as cutoff values, 313 DEGs between unshaded and shaded lettuces were identified. Among the DEGs, 254 and 59 were upregulated in unshaded and shaded lettuce, respectively, and clustered by treatment (Fig. 3). There was a 0.86 Spearman coefficient $(P<$ 0.001 ) between RNAseq and qRT-PCR data, indicating that the qRT-PCR data validated the RNAseq results, despite using only two biological replicates per treatment.

Analyses of identified DEGs using GO terms sorted their putative gene products into 10 biological process, three cellular component, and three molecular function categories (Supplemental Table 2). The greatest numbers of DEGs were involved in processes such as plasma membrane function, extracellular region metabolism (gene products not attached to the cell surface), 
A
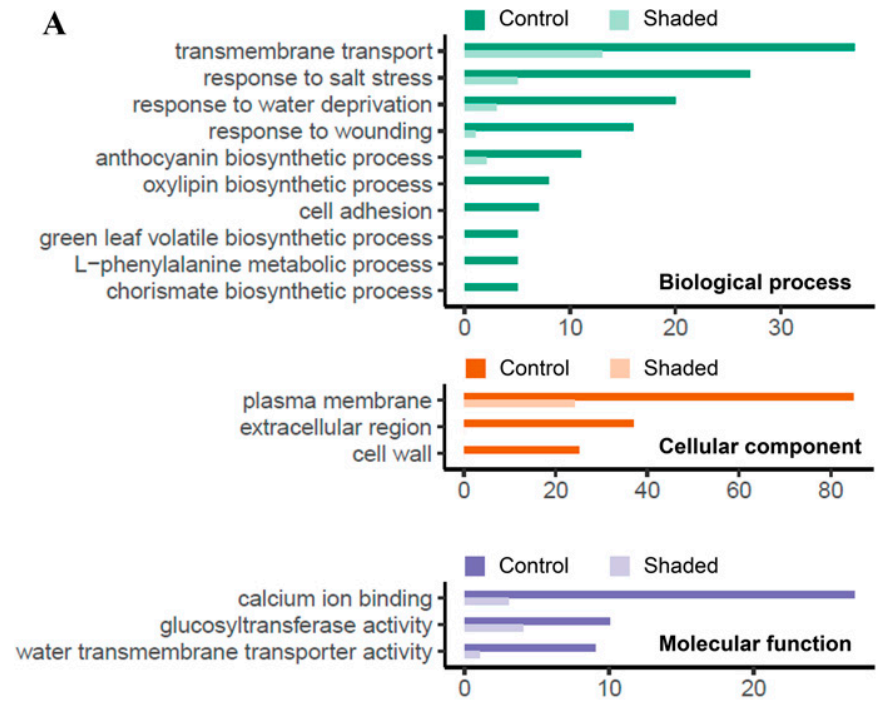

B

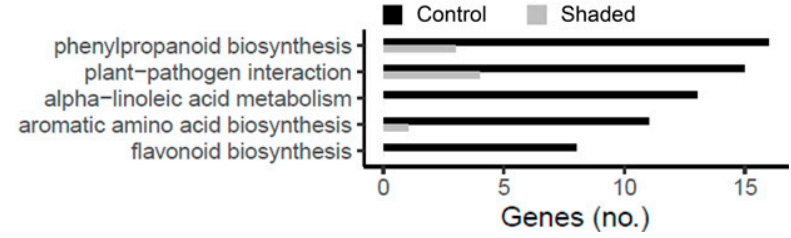

Fig. 4. Functions of differentially expressed genes (DEGs) between unshaded control and shaded lettuce identified from RNA sequencing and based on (A) Gene Ontology project (GO) and (B) Kyoto Encyclopedia of Genes and Genomes analyses. DEGs in the GO analyses were categorized as biological processes, cellular components, and molecular functions.

transmembrane transport, calcium ion binding, response to salt stress, and response to water deprivation (Fig. 4A). These DEGs under the enriched GO terms were mostly upregulated in unshaded controls compared with shaded lettuce. An insignificant number of genes were upregulated in shaded compared with unshaded lettuce.

KEGG enrichment analysis distributed DEGs into five categories, in which all DEGs were upregulated in unshaded compared with shaded lettuce (Fig. 4B). The categories included phenylpropanoid biosynthesis, plant-pathogen interaction, $\alpha$-linoleic acid metabolism, aromatic amino acid metabolism, and flavonoid biosynthesis.

Examination of genes related to photosynthesis and carbohydrate metabolism showed that a few genes were upregulated in unshaded compared with shaded lettuce (Table 1), including those coding for early light-induced proteins and the RuBisCO small and large subunits. Only $19 \%$ of differentially expressed genes were upregulated in shaded compared with unshaded control lettuce (Supplemental Table 3). Genes related to phenylpropanoid and flavonoid biosynthesis were upregulated in unshaded compared with shaded lettuce. No genes related to bitterness, such as squalene synthase (Testone et al., 2019) or sesquiterpene synthase (Bennett et al., 2002), were differentially expressed between unshaded and shaded lettuce.

\section{Discussion}

Shading decreased average temperatures of lettuce compared with unshaded controls (Fig. 1A and B) and was most effective in reducing temperature when leaf temperatures were above $35^{\circ} \mathrm{C}$. The heat-tolerant lettuce cultivars, Sparx and Salvius, grew well in unshaded conditions in both locations and years. However, shade reduced lettuce fresh weights of both tested cultivars (Fig. 2A). These results agree with those described by Zhao and Carey (2009) for romaine lettuce grown under high tunnels shaded with $39 \%$ white shadecloth, which had lesser head fresh weights compared to those grown in the open field; the white shadecloth decreased leaf surface temperature. However, our results contrast with those observed for butterhead lettuce shaded with $50 \%$ black netting (Ilić et al., 2017), and green- and red-leaf lettuce shaded with $50 \%$ black netting ( $\mathrm{Li}$ et al., 2017), in which head fresh weights were greater than those grown in the open field. Li et al. (2017) reported that lettuce head dry weights did not differ among treatments, suggesting that differences among treatments in their study may have been due to differences in water content.

Unshaded 'Sparx' and 'Salvius' lettuces were rated by sensory evaluation participants as sweeter than shaded counterparts (Fig. 2D). These evaluations were positively correlated with the higher total sugars contents of unshaded compared with shaded lettuce (Fig. 2C) and the upregulation of genes related to glucose metabolism (Table 1). Our data were similar to results reported for soluble sugars by Mastilović et al. (2019). Unshaded lettuce has previously been shown to be more bitter than shaded lettuce (Zhao and Carey, 2009), but no difference in bitterness was discerned between the shaded and unshaded lettuce cultivars used in this study.

The higher content of sugars in the unshaded lettuce may be attributed to higher photosynthetic rates compared with shaded lettuce, although we did not measure lettuce photosynthetic rates.

Table 1. Differentially expressed genes with Gene Ontology project (GO) functions associated with chlorophyll biosynthesis, photosynthesis, and carbohydrate metabolism. GO analyses were performed on data from RNA sequencing results using the goseq R Bioconductor software package (Young et al., 2010). A positive $\log _{2}$ value indicates that the gene was upregulated in unshaded lettuce.

\begin{tabular}{|c|c|c|c|}
\hline GO identifier & $\log _{2}$ (fold-change) & GO term & Gene annotation \\
\hline \multicolumn{4}{|c|}{ Chlorophyll biosynthesis } \\
\hline LOC111915584 & 2.63 & Chlorophyll biosynthetic process & 1-deoxy-D-xylulose-5-phosphate synthase \\
\hline LOC111881935 & 2.29 & Regulation of chlorophyll biosynthetic process & Early light-induced protein \\
\hline \multicolumn{4}{|l|}{ Photosynthesis } \\
\hline LOC111908115 & 2.55 & Photosynthetic electron transport in photosystem I & Protein proton gradient regulation \\
\hline \multicolumn{4}{|c|}{ Carbohydrate metabolism } \\
\hline LOC111908252 & 2.13 & Carbon fixation & RuBisCO small subunit \\
\hline LOC111898611 & 2.87 & Carbon fixation & RuBisCO large subunit \\
\hline
\end{tabular}


These results suggest that greater photosynthesis in the unshaded lettuce, and consequently higher accumulation of sugars, may have resulted in sweeter unshaded than shaded lettuce. Shading treatments affected lettuce chlorophyll b content (Fig. 2F), but not total chlorophyll or chlorophyll a (Fig. 2E) content, in our study. Shaded lettuce had higher mean chlorophyll $b$ content than unshaded lettuce, but the difference between treatments was small (means of $1.04 \mu \mathrm{g} \cdot \mathrm{mL}^{-1}$ for the unshaded vs. $1.18 \mu \mathrm{g} \cdot \mathrm{mL}^{-1}$ for the shaded lettuce). These data are different from those reported by Ilić and Fallik (2017) and Ilić et al. (2017) for butterhead lettuce, in which shading with black netting increased chlorophyll a, chlorophyll $\mathrm{b}$, and carotenoid contents on a fresh weight basis compared with unshaded lettuce. Shade-tolerant species have been shown to have higher proportions of chlorophyll $b$ relative to chlorophyll a (Boardman, 1977). It may be that the lettuce cultivars used in this study are more shade tolerant than the butterhead lettuce studied by Ilić et al. (2017). Also, genes associated with rubisco subunits were upregulated in unshaded lettuce (Table 1), which may have led to greater plant growth and soluble sugar accumulation under high light and high temperature in unshaded conditions. The higher fresh weights and sweetness of the cultivars grown in unshaded compared with shaded conditions in our study may be attributed to many different mechanisms, including carbohydrate metabolic processes, two of which were also upregulated in unshaded compared with shaded lettuce (Table 1). The extent to which RNAs were translated into active proteins could be studied in future work.

The differing results among the literature and our results highlight variability among genotypes in interactions with the environment. While greater fresh weight under shading conditions were observed for the cultivars Tizian (Ilić et al., 2017), Two Star (green-leaf) and New Red Fire [red leaf (Li et al., 2017)], opposite results were observed for the cultivars used in this study. Lafta et al. (2021) found significant genotype $\times$ environment differences in head weight, core length, and head diameter, among other traits in crisphead lettuce. The ability of the cultivars used in this study to tolerate heat may be related to modifications in many pathways that are involved in photosynthesis and secondary metabolism (Fig. 3, Table 1). As temperatures increase, lettuce growers will need to adapt by using as many tools as possible, including growing heat-tolerant cultivars. It could be possible that heat-tolerance limits of lettuce may be extended by growing them under shade.

\section{Literature Cited}

Andrews, S. 2010. FastQC: A quality control tool for high throughput sequence data. 15 Apr. 2020. <http://www.bioinformatics.babraham. ac.uk/projects/fastqc $>$.

Bates, D., M. Maechler, B. Bolker, and S. Walker. 2015. Fitting linear mixed-effects models using lme4. J. Stat. Softw. 67:1-48, https://doi. org/10.18637/jss.v067.i01.

Bennett, M.H., J.W. Mansfield, M.J. Lewis, and M.H. Beale. 2002. Cloning and expression of sesquiterpene synthase genes from lettuce (Lactuca sativa L.). Phytochemistry 60:255-261. https://doi.org/ 10.1016/s0031-9422(02)00103-6.

Boardman, N.K. 1977. Comparative photosynthesis of sun and shade plants. Annu. Rev. Plant Physiol. 28:355-377, https://doi.org/10.1146/ annurev.pp.28.060177.002035.

Bolger, A.M., M. Lohse, and B. Usadel. 2014. Trimmomatic: A flexible trimmer for Illumina sequence data. Bioinformatics 30: 2114-2120, https://doi.org/10.1093/bioinformatics/btu170.
Bunning, M.L., P.A. Kendall, M.B. Stone, F.H. Stonaker, and C. Stushnoff. 2010. Effects of seasonal variation on sensory properties and total phenolic content of 5 lettuce cultivars. J. Food Sci. 75: 156-161, https://doi.org/10.1111/j.1750-3841.2010.01533.x.

Chadwick, M., F. Gawthrop, R.W. Michelmore, C. Wagstaff, and L. Methven. 2016. Perception of bitterness, sweetness and liking of different genotypes of lettuce. Food Chem. 197:66-74, https://doi.org/ 10.1016/j.foodchem.2015.10.105.

Drewnowski, A. and C. Gomez-Carneros. 2000. Bitter taste, phytonutrients, and the consumer: A review. Am. J. Clin. Nutr. 72: 1424-1435, https://doi.org/10.1093/ajcn/72.6.1424.

Driedonks, N., I. Rieu, and W.H. Vriezen. 2016. Breeding for plant heat tolerance at vegetative and reproductive stages. Plant Reprod. 29:67-79, https://doi.org/10.1007/s00497-016-0275-9.

Han, Y., Z. Chen, L. Shanshan, K. Ning, X. Ji, X. Liu, Q. Wang, R. Liu, S. Fan, and X. Zhang. 2016. MADS-Box genes and gibberellins regulate bolting in lettuce (Lactuca sativa L.). Front. Plant Sci. 7:1889, https://doi.org/10.3389/fpls.2016.01889.

Holmes, S.C., D.E. Wells, J.E. Pickens, and J.M. Kemble. 2019. Selection of heat-tolerant lettuce (Lactuca sativa L.) cultivars grown in deep water culture and their marketability. Horticulturae 5:50, https://doi.org/10.3390/horticulturae5030050.

Ilić, S.Z. and E. Fallik. 2017. Light quality manipulation improves vegetable quality at harvest and postharvest: A review. Environ. Exp. Bot. 139:79-90, https://doi.org/10.1016/j.envexpbot.2017.04.006.

Ilić, S.Z., L. Milenković, A. Dimitrijević, L. Stanojević, D. Cvetković, Ž. Kevrešan, E. Fallik, and J. Mastilović. 2017. Light modification by color nets improve quality of lettuce from summer production. Scientia Hort. 226:389-397, https://doi.org/10.1016/j.scienta.2017.09.009.

Karalus, M., C. Pontet, and Z. Vickers. 2010. Experimentally created intensity scales for the five basic tastes: Sweet, sour, salty, bitter and umami. 1 Oct. 2021. <https://sensorycenter.cfans.umn.edu/calibratedscales-used-umn-sensory-center $>$.

Kim, D., J.M. Paggi, C. Park, C. Bennett, and S.L. Salzberg. 2019. Graph-based genome alignment and genotyping with HISAT2 and HISAT-genotype. Nat. Biotechnol. 37:907-915, https://doi.org/ 10.1038/s41587-019-0201-4.

Lafta, A., G. Sandoya, and B. Mou. 2021. Genetic variation and genotype by environment interaction for heat tolerance in crisphead lettuce. HortScience 56:126-135, https://doi.org/10.21273/HORTSCI15209-20.

Li, T., G. Bi, J. LeCompte, T.C. Barickman, and B.B. Evans. 2017. Effect of colored shadecloth on the quality and yield of lettuce and snapdragon. HortTechnology 27:860-867, https://doi.org/10.21273/ HORTTECH03809-17.

Liao, Y., G.K. Smyth, and W. Shi. 2019. The R package Rsubread is easier, faster, cheaper and better for alignment and quantification of RNA sequencing reads. Nucleic Acids Res. 47:e47, https://doi.org/ 10.1093/nar/gkz114.

Livak, K.J. and T.D. Schmittgen. 2001. Analysis of relative gene expression data using real-time quantitative PCR and the $2 \Delta \Delta \mathrm{C}(\mathrm{T})$ method. Methods 25:402-408, https://doi.org/10.1006/meth.2001.1262.

Mastilović, J., Ž. Kevrešan, A. Jakšić, I. Milovanović, R. Trajković, M. Stanković, L. Milenković, and Z.S. Ilić. 2019. Influence of light modification on postharvest butter lettuce quality: Differences between external and internal leaves. Zemdirbyste-Agr. 106:65-72, https://doi.org/10.13080/z-a.2019.106.009.

Price, K.R., M.S. DuPont, R. Shepherd, H.W.-S. Chan, and G.S. Fenwick. 1990. Relationship between the chemical and sensory properties of exotic salad crops-coloured lettuce (Lactuca sativa) and chicory (Chicorum intybus). J. Sci. Food Agr. 53:185-192, https:// doi.org/10.1002/jsfa.2740530206.

Reyes-Chin-Wo, S., Z. Wang, X. Yang, A. Kozik, S. Arikit, C. Song, L. Xia, L. Froenicke, D.O. Lavelle, M.J. Truco, R. Xia, S. Zhu, C. $\mathrm{Xu}, \mathrm{H}$. Xu, X. Xu, K. Cox, I. Korf, B.C. Meyers, and R.W. Michelmore. 2017. Genome assembly with in vitro proximity ligation data 
and whole-genome triplication in lettuce. Nat. Commun. 8:14953, https://doi.org/10.1038/ncomms14953.

Robinson, M.D., D.J. McCarthy, and G.K. Smyth. 2010. edgeR: A Bioconductor package for differential expression analysis of digital gene expression data. Bioinformatics 26:139-140, https://doi.org/ 10.1093/bioinformatics/btp616.

Simonne, A., E. Simonne, R. Eitenmiller, and C.H. Coker. 2002. Bitterness and composition of lettuce varieties grown in the southeastern United States. HortTechnology 12:721-726, https://doi.org/10.21273/ HORTTECH.12.4.721.

Sumanta, N., C.I. Haque, J. Nishika, and R. Suprakash. 2014. Spectrophotometric analysis of chlorophylls and carotenoids from commonly grown fern species by using various extracting solvents. Res. J. Chem. Sci. 4:63-69, https://doi.org/10.1055/ s-0033-1340072.

Testone, G., G. Mele, E. di Giacomo, G.C. Tenore, M. Gonnella, C. Nicolodi, G. Frugis, M.A. Iannelli, G. Arnesi, A. Schiappa, T. Biancari, and D. Giannino. 2019. Transcriptome driven characterization of curly- and smooth-leafed endives reveals molecular differences in the sesquiterpenoid pathway. Hort. Res. 6:1-19, https://doi.org/ 10.1038/s41438-018-0066-6.
U.S. Department of Agriculture, National Agricultural Statistics Service. 2020. Vegetables 2019 summary. 1 Oct. 2021. <https://www. nass.usda.gov/Publications/Todays_Reports/reports/vegean20.pdf $>$.

Waycott, W. and E.J. Ryder. 1993. Adaptation of lettuce to hightemperature environments, p. 285-295. In: C.G. Kuo (ed.). Adaptation of food crops to temperature and water stress: Proceedings of an international symposium. AVRDC Publ. No. 410/93. Asian Vegetable Res. Dev. Cent., Taipei, Taiwan.

Ye, J., G. Coulouris, I. Zaretskaya, I. Cutcutache, S. Rozen, and T.L. Madden. 2012. Primer-BLAST: A tool to design target-specific primers for polymerase chain reaction. BMC Bioinformatics 13:134, https://doi.org/10.1186/1471-2105-13-134pmid:22708584.

Young, M.D., M.J. Wakefield, G.K. Smyth, and A. Oshlack. 2010. Gene ontology analysis for RNA-seq: Accounting for selection bias. Genome Biol. 11:R14, https://doi.org/10.1186/gb-2010-11-2-r14.

Yu, G., L. Wang, Y. Han, and Q. He. 2012. clusterProfiler: An R package for comparing biological themes among gene clusters. OMICS 16:284-287, https://doi.org/10.1089/omi.2011.0118.

Zhao, X. and E.E. Carey. 2009. Summer production of lettuce, and microclimate in high tunnel and open field plots in Kansas. HortTechnology 19:113-119, https://doi.org/10.21273/HORTSCI.19.1.113. 


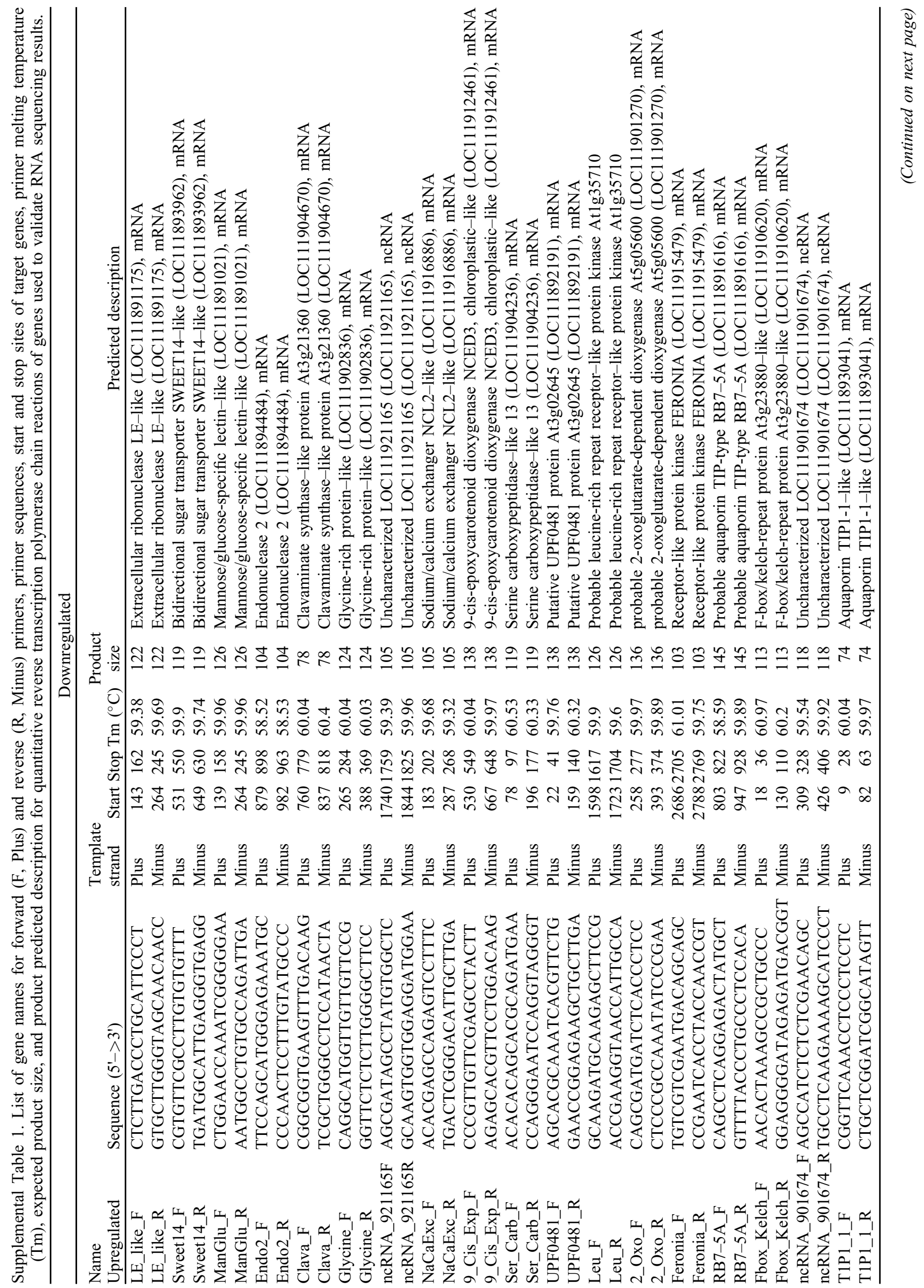




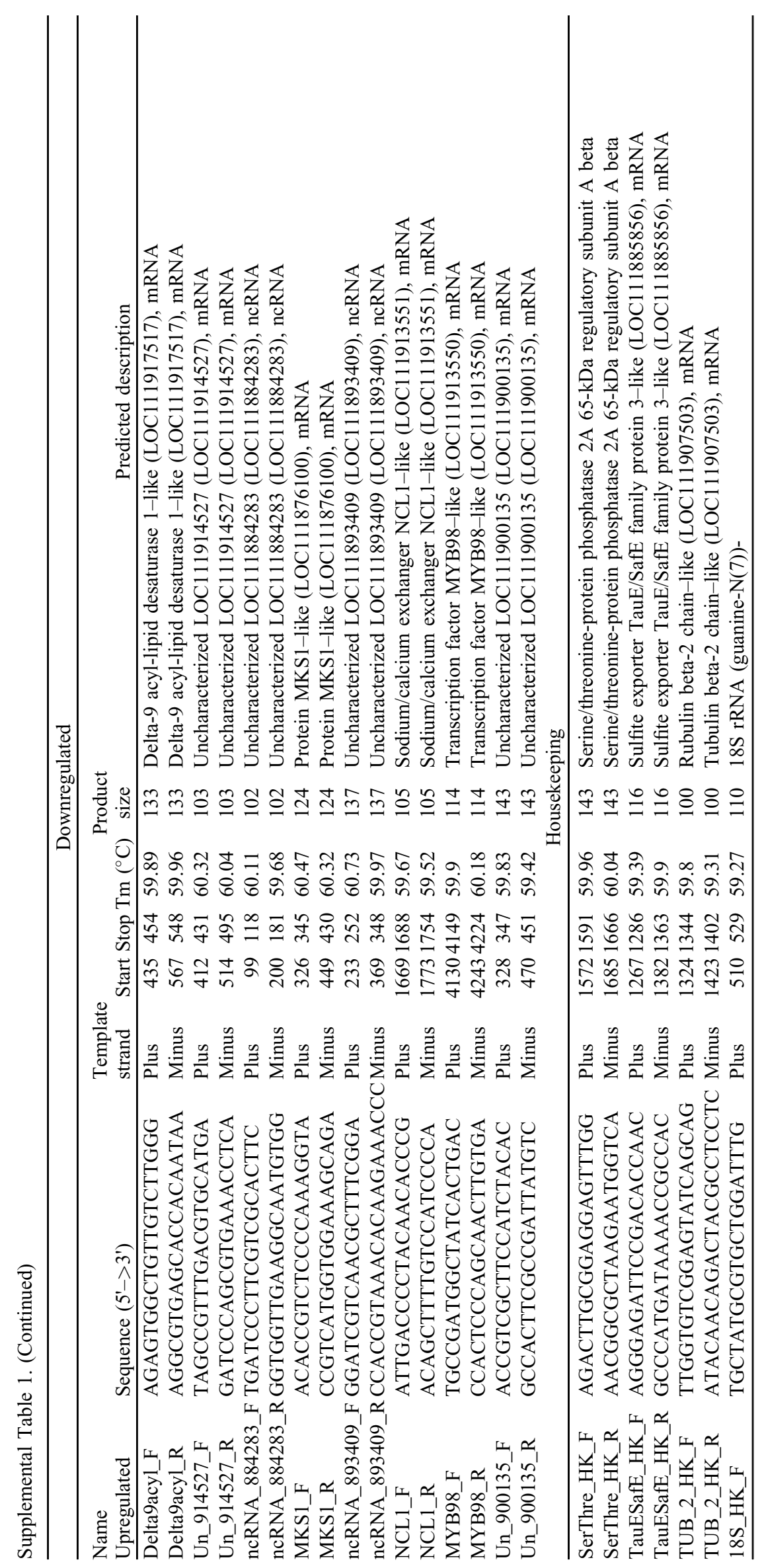


Supplemental Table 2. List of Gene Ontology project (GO) unique identifiers, names (ID), and term names of all genes determined by RNA sequencing analyses to be differentially expressed between unshaded control and shaded lettuce. Differentially expressed genes were identified using the Bioconductor edgeR software package (Robinson et al., 2010). Enriched GO terms were determined using a false discovery rate $<0.05$ and generated using the Bioconductor goseq R software package (Young et al., 2010).

\begin{tabular}{|c|c|c|}
\hline Unique identifier & ID & GO term \\
\hline LOC111876247 & GO:0046872 & Metal ion binding \\
\hline LOC111876394 & GO:0010088 & Phloem development \\
\hline LOC111876394 & GO:0016021 & Integral component of membrane \\
\hline LOC111876517 & GO:0055085 & Transmembrane transport \\
\hline LOC111876517 & GO:0005886 & Plasma membrane \\
\hline LOC111876517 & GO:0008308 & Voltage-gated anion channel activity \\
\hline LOC111876517 & GO:0016021 & Integral component of membrane \\
\hline LOC111876517 & GO:0006873 & Cellular ion homeostasis \\
\hline LOC111876517 & GO:0015698 & Inorganic anion transport \\
\hline LOC111876728 & GO:0003887 & DNA-directed DNA polymerase activity \\
\hline LOC111876728 & GO:0071897 & DNA biosynthetic process \\
\hline LOC111876728 & GO:0005634 & Nucleus \\
\hline LOC111876728 & GO:0006260 & DNA replication \\
\hline LOC111876728 & GO:0051539 & 4 iron, 4 sulfur cluster binding \\
\hline LOC111876728 & GO:0022616 & DNA strand elongation \\
\hline LOC111876728 & GO:0019103 & Pyrimidine nucleotide binding \\
\hline LOC111876728 & GO:0000428 & DNA-directed RNA polymerase complex \\
\hline LOC111876728 & GO:0003677 & DNA binding \\
\hline LOC111876728 & GO:0003896 & DNA primase activity \\
\hline LOC111876728 & GO:0030894 & Replisome \\
\hline LOC111876728 & GO:0042575 & DNA polymerase complex \\
\hline LOC111876728 & GO:0046872 & Metal ion binding \\
\hline LOC111876728 & GO:0003682 & Chromatin binding \\
\hline LOC111876728 & GO:0070013 & Intracellular organelle lumen \\
\hline LOC111876728 & GO:0043233 & Organelle lumen \\
\hline LOC111876728 & GO:0009965 & Leaf morphogenesis \\
\hline LOC111876728 & GO: 1903047 & Mitotic cell cycle process \\
\hline LOC111876728 & GO:0017076 & Purine nucleotide binding \\
\hline LOC111876728 & GO:0032774 & RNA biosynthetic process \\
\hline LOC111876787 & GO:0016881 & Acid-amino acid ligase activity \\
\hline LOC111876787 & GO:0005737 & Cytoplasm \\
\hline LOC111876787 & GO:0102057 & Jasmonoyl-valine synthetase activity \\
\hline LOC111876787 & GO:0102053 & (-)-jasmonoyl-isoleucine synthetase activity \\
\hline LOC111876787 & GO:0102058 & Jasmonoyl-leucine synthetase activity \\
\hline LOC111877039 & GO:0031012 & Extracellular matrix \\
\hline LOC111877039 & GO:0030574 & Collagen catabolic process \\
\hline LOC111877039 & GO:0004222 & Metalloendopeptidase activity \\
\hline LOC111877039 & GO:0030198 & Extracellular matrix organization \\
\hline LOC111877039 & GO:0008270 & Zinc ion binding \\
\hline LOC111877039 & GO:0006508 & Proteolysis \\
\hline LOC111877141 & GO:0016787 & Hydrolase activity \\
\hline LOC111877485 & GO:0005507 & Copper ion binding \\
\hline LOC111877485 & GO:0030001 & Metal ion transport \\
\hline LOC111877485 & GO:0016021 & Integral component of membrane \\
\hline LOC111877485 & GO:0019829 & ATPase-coupled cation transmembrane transporter activity \\
\hline LOC111877485 & GO:0035434 & Copper ion transmembrane transport \\
\hline LOC111877485 & GO:0043682 & Copper transmembrane transporter activity, phosphorylative mechanism \\
\hline LOC111877485 & GO:0072511 & Divalent inorganic cation transport \\
\hline LOC111877485 & GO:0005524 & ATP binding \\
\hline LOC111877830 & GO:0016787 & Hydrolase activity \\
\hline LOC111877830 & GO:0043531 & ADP binding \\
\hline LOC111879316 & GO:0009506 & Plasmodesma \\
\hline LOC111879316 & GO:0046777 & Protein autophosphorylation \\
\hline LOC111879316 & GO:0004672 & Protein kinase activity \\
\hline
\end{tabular}


Supplemental Table 2. (Continued)

\begin{tabular}{|c|c|c|}
\hline Unique identifier & ID & GO term \\
\hline LOC111879316 & GO:0005886 & Plasma membrane \\
\hline LOC111879316 & GO:0016021 & Integral component of membrane \\
\hline LOC111879403 & GO:0005737 & Cytoplasm \\
\hline LOC111879403 & GO:0009651 & Response to salt stress \\
\hline LOC111879403 & GO:0003968 & RNA-directed 5'-3' RNA polymerase activity \\
\hline LOC111879403 & GO:0009409 & Response to cold \\
\hline LOC111879403 & GO:0042651 & Thylakoid membrane \\
\hline LOC111879403 & GO:0001172 & Transcription, RNA-templated \\
\hline LOC111879403 & GO:0039694 & Viral RNA genome replication \\
\hline LOC111879403 & GO:0098588 & Bounding membrane of organelle \\
\hline LOC111879403 & GO:0031984 & Organelle subcompartment \\
\hline LOC111880353 & GO:0016787 & Hydrolase activity \\
\hline LOC111880353 & GO:0016021 & Integral component of membrane \\
\hline LOC111880881 & GO:0010091 & Trichome branching \\
\hline LOC111880979 & GO:0046983 & Protein dimerization activity \\
\hline LOC111880979 & GO:0005634 & Nucleus \\
\hline LOC111880979 & GO:0003723 & RNA binding \\
\hline LOC111880979 & GO:0016021 & Integral component of membrane \\
\hline LOC111881022 & GO:0106311 & NA \\
\hline LOC111881022 & GO:0006468 & Protein phosphorylation \\
\hline LOC111881022 & GO:0005886 & Plasma membrane \\
\hline LOC111881022 & GO:0106310 & NA \\
\hline LOC111881492 & GO:0005634 & Nucleus \\
\hline LOC111881492 & GO:0080030 & Methyl indole-3-acetate esterase activity \\
\hline LOC111881492 & GO:0009820 & Alkaloid metabolic process \\
\hline LOC111881492 & GO:0016021 & Integral component of membrane \\
\hline LOC111881554 & GO:0004672 & Protein kinase activity \\
\hline LOC111881554 & GO:0006468 & Protein phosphorylation \\
\hline LOC111881554 & GO:0016021 & Integral component of membrane \\
\hline LOC111881554 & GO:0005886 & Plasma membrane \\
\hline LOC111881554 & GO:0005524 & ATP binding \\
\hline LOC111881554 & GO:0005525 & GTP binding \\
\hline LOC111881554 & GO:0003676 & Nucleic acid binding \\
\hline LOC111881702 & GO:0016021 & Integral component of membrane \\
\hline LOC111881702 & GO:0003735 & Structural constituent of ribosome \\
\hline LOC111881702 & GO:0006412 & Translation \\
\hline LOC111881702 & GO:0005840 & Ribosome \\
\hline LOC111881935 & GO:0009507 & Chloroplast \\
\hline LOC111881935 & GO:0015979 & Photosynthesis \\
\hline LOC111881935 & GO:0046872 & Metal ion binding \\
\hline LOC111881935 & GO:0071491 & Cellular response to red light \\
\hline LOC111881935 & GO:0009579 & Thylakoid \\
\hline LOC111881935 & GO:0071490 & Cellular response to far red light \\
\hline
\end{tabular}


Supplemental Table 2. (Continued)

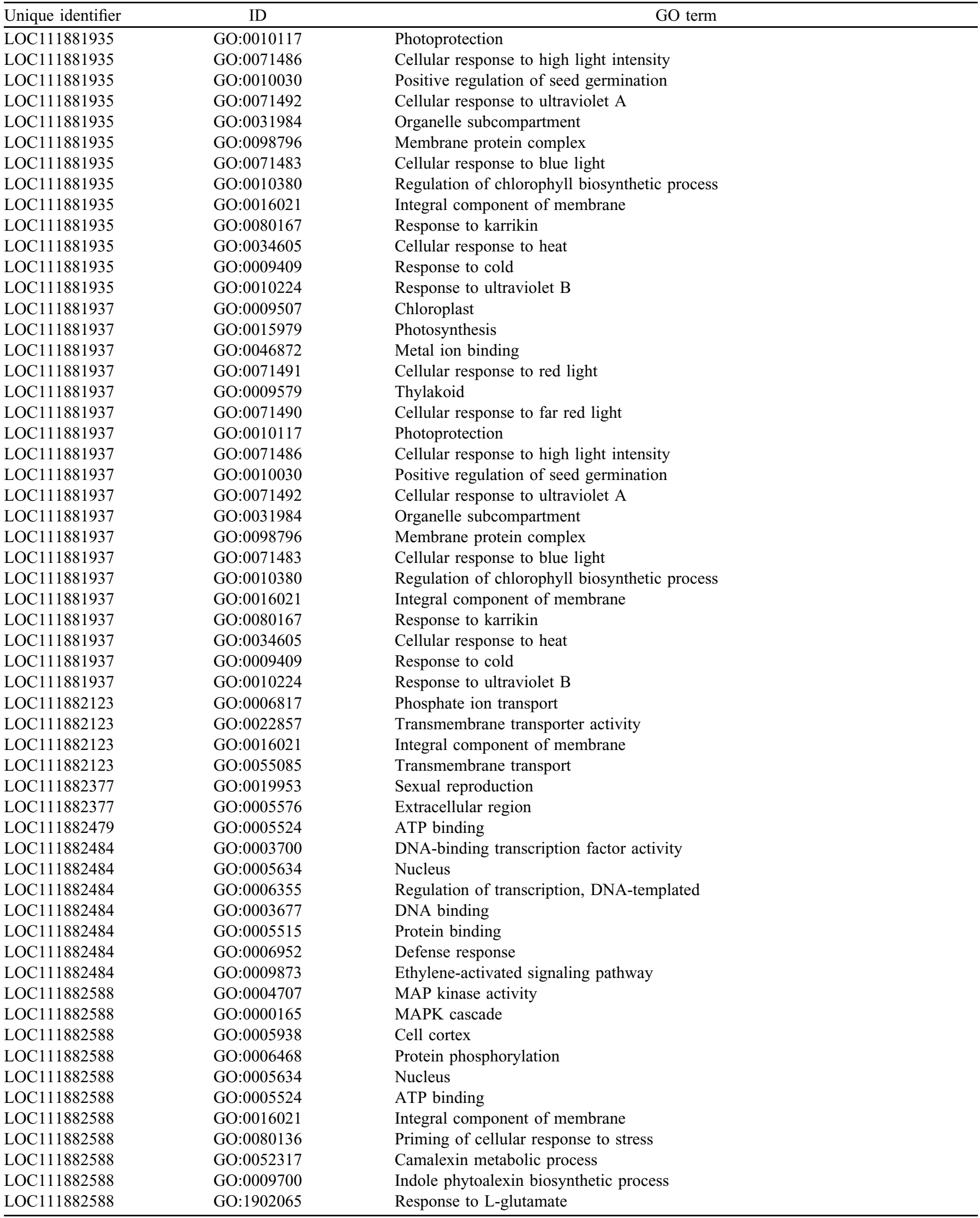


Supplemental Table 2. (Continued)

\begin{tabular}{|c|c|c|}
\hline Unique identifier & ID & GO term \\
\hline LOC111882588 & GO:0005515 & Protein binding \\
\hline LOC111882588 & GO:1901002 & Positive regulation of response to salt stress \\
\hline LOC111882588 & GO:0022857 & Transmembrane transporter activity \\
\hline LOC111882588 & GO:0050826 & Response to freezing \\
\hline LOC111882588 & GO:0048481 & Plant ovule development \\
\hline LOC111882588 & GO:0010183 & Pollen tube guidance \\
\hline LOC111882588 & GO:0010224 & Response to ultraviolet B \\
\hline LOC111882588 & GO:0009555 & Pollen development \\
\hline LOC111882588 & GO:0009414 & Response to water deprivation \\
\hline LOC111882588 & GO:0050832 & Defense response to fungus \\
\hline LOC111882588 & GO:0006970 & Response to osmotic stress \\
\hline LOC111882588 & GO:0009611 & Response to wounding \\
\hline LOC111882588 & GO:0009626 & Plant-type hypersensitive response \\
\hline LOC111882588 & GO:0009738 & Abscisic acid-activated signaling pathway \\
\hline LOC111882588 & GO:0006857 & Oligopeptide transport \\
\hline LOC111882588 & GO:0055085 & Transmembrane transport \\
\hline LOC111882695 & GO:0016787 & Hydrolase activity \\
\hline LOC111882721 & GO:0005886 & Plasma membrane \\
\hline LOC111882721 & GO:0034154 & Toll-like receptor 7 signaling pathway \\
\hline LOC111882721 & GO:0003727 & Single-stranded RNA binding \\
\hline LOC111882721 & GO:0002755 & MyD88-dependent toll-like receptor signaling pathway \\
\hline LOC111882721 & GO:0004888 & Transmembrane signaling receptor activity \\
\hline LOC111882721 & GO:0016021 & Integral component of membrane \\
\hline LOC111882972 & GO:0055085 & Transmembrane transport \\
\hline LOC1 11882972 & GO:0005372 & Water transmembrane transporter activity \\
\hline LOC111882972 & GO:0005774 & Vacuolar membrane \\
\hline LOC111883018 & GO:0042626 & ATPase-coupled transmembrane transporter activity \\
\hline LOC111883018 & GO:0055085 & Transmembrane transport \\
\hline LOC 111883018 & GO:0016021 & Integral component of membrane \\
\hline LOC111883018 & GO:0005524 & ATP binding \\
\hline LOC111883438 & GO:0005975 & Carbohydrate metabolic process \\
\hline LOC111883612 & GO:0006857 & Oligopeptide transport \\
\hline LOC111883612 & GO:0022857 & Transmembrane transporter activity \\
\hline LOC111883612 & GO:0016021 & Integral component of membrane \\
\hline LOC111883612 & GO:0006817 & Phosphate ion transport \\
\hline LOC111883612 & GO:0055085 & Transmembrane transport \\
\hline LOC111883728 & GO:0046872 & Metal ion binding \\
\hline LOC111883728 & GO:0005774 & Vacuolar membrane \\
\hline LOC111883728 & GO:0009507 & Chloroplast \\
\hline LOC111883728 & GO:0005886 & Plasma membrane \\
\hline LOC111883899 & GO:0003700 & DNA-binding transcription factor activity \\
\hline LOC111883899 & GO:0005634 & Nucleus \\
\hline LOC111883899 & GO:0006355 & Regulation of transcription, DNA-templated \\
\hline LOC111883899 & GO:0003677 & DNA binding \\
\hline
\end{tabular}


Supplemental Table 2. (Continued)

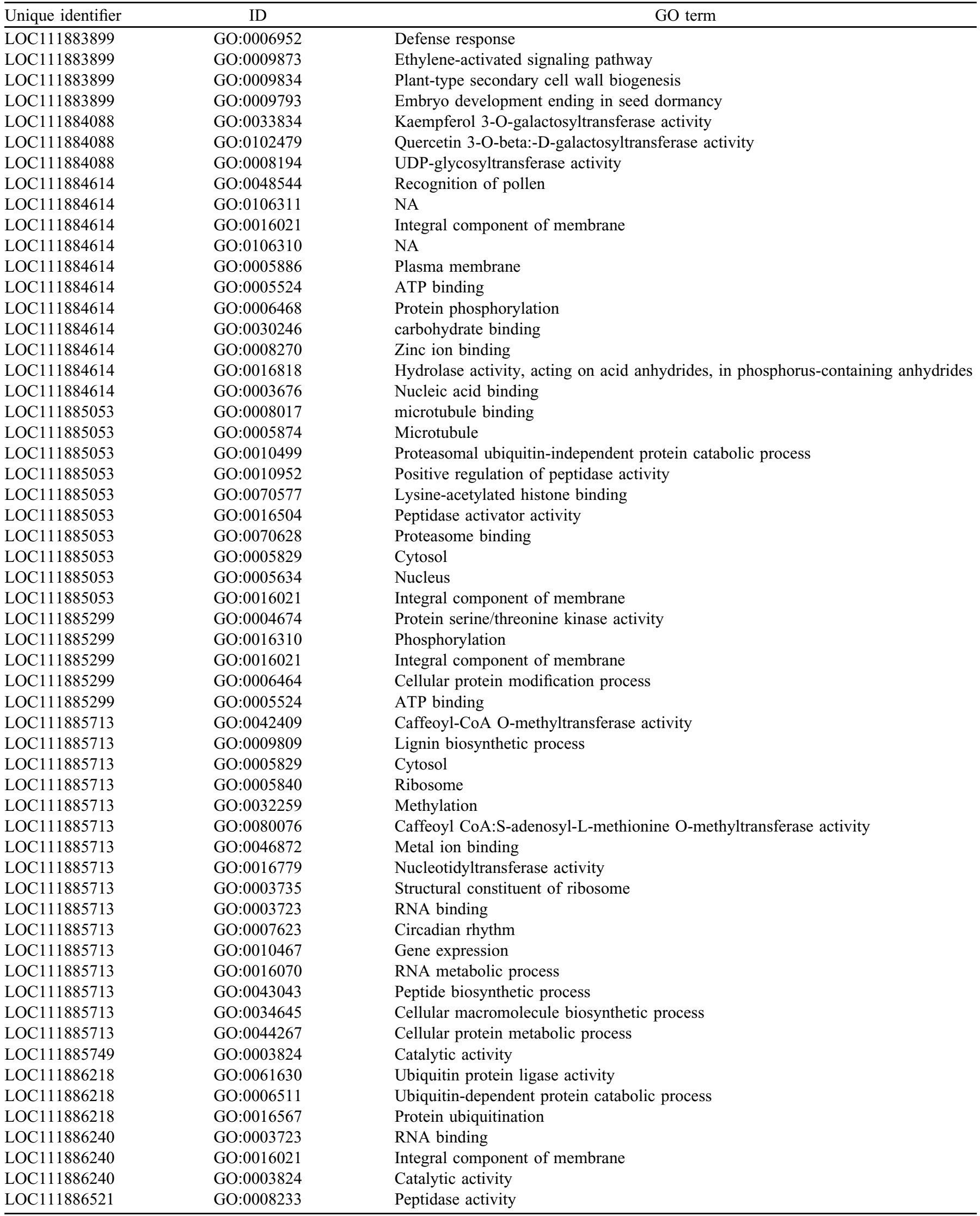


Supplemental Table 2. (Continued)

\begin{tabular}{|c|c|c|}
\hline Unique identifier & ID & GO term \\
\hline LOC111886521 & GO:0006508 & Proteolysis \\
\hline LOC111886521 & GO:0005524 & ATP binding \\
\hline LOC111886524 & GO:0016567 & Protein ubiquitination \\
\hline LOC111886524 & GO:0005829 & Cytosol \\
\hline LOC111886524 & GO:0004842 & Ubiquitin-protein transferase activity \\
\hline LOC111886530 & GO:0043565 & Sequence-specific DNA binding \\
\hline LOC111886530 & GO:0005634 & Nucleus \\
\hline LOC111886530 & GO:0006355 & Regulation of transcription, DNA-templated \\
\hline LOC111886530 & GO:0003700 & DNA-binding transcription factor activity \\
\hline LOC111886530 & GO:0001067 & Regulatory region nucleic acid binding \\
\hline LOC111886530 & GO:0003690 & Double-stranded DNA binding \\
\hline LOC111886670 & GO:0000027 & Ribosomal large subunit assembly \\
\hline LOC 111886670 & GO:1990904 & Ribonucleoprotein complex \\
\hline LOC111886670 & GO:0016021 & Integral component of membrane \\
\hline LOC111886856 & GO:0016788 & Hydrolase activity, acting on ester bonds \\
\hline LOC111886948 & GO:0043565 & Sequence-specific DNA binding \\
\hline LOC111886948 & GO:0005634 & Nucleus \\
\hline LOC111886948 & GO:0006355 & Regulation of transcription, DNA-templated \\
\hline LOC111886948 & GO:0003700 & DNA-binding transcription factor activity \\
\hline LOC111886948 & GO:0001067 & Regulatory region nucleic acid binding \\
\hline LOC111886948 & GO:0016740 & Transferase activity \\
\hline LOC111886948 & GO:0003690 & Double-stranded DNA binding \\
\hline LOC111887525 & GO:0016887 & ATPase activity \\
\hline LOC 111887525 & GO:0016021 & Integral component of membrane \\
\hline LOC111887525 & GO:0005524 & ATP binding \\
\hline LOC111887623 & GO:0004190 & Aspartic-type endopeptidase activity \\
\hline LOC111887623 & GO:0006508 & Proteolysis \\
\hline LOC 111887623 & GO:0005576 & Extracellular region \\
\hline LOC111887623 & GO:0016021 & Integral component of membrane \\
\hline LOC111887689 & GO:0016747 & Transferase activity, transferring acyl groups other than amino-acyl groups \\
\hline LOC111887815 & GO:0016042 & Lipid catabolic process \\
\hline LOC111887815 & GO:0045735 & Nutrient reservoir activity \\
\hline LOC111887815 & GO:0005773 & Vacuole \\
\hline LOC111887815 & GO:0016787 & Hydrolase activity \\
\hline LOC111887815 & GO:0016740 & Transferase activity \\
\hline LOC111887815 & GO:0016021 & Integral component of membrane \\
\hline LOC111887879 & GO:0048046 & Apoplast \\
\hline LOC111887879 & GO:0042973 & Glucan endo-1,3-beta-D-glucosidase activity \\
\hline LOC111887879 & GO:0005975 & Carbohydrate metabolic process \\
\hline LOC111887879 & GO:0016021 & Integral component of membrane \\
\hline LOC111887879 & GO:0016874 & Ligase activity \\
\hline LOC111887884 & GO:0048046 & Apoplast \\
\hline LOC111887884 & GO:0042973 & Glucan endo-1,3-beta-D-glucosidase activity \\
\hline
\end{tabular}


Supplemental Table 2. (Continued)

\begin{tabular}{|c|c|c|}
\hline Unique identifier & ID & GO term \\
\hline LOC111887884 & GO:0005975 & Carbohydrate metabolic process \\
\hline LOC111887884 & GO:0016021 & Integral component of membrane \\
\hline LOC111887884 & GO:0016874 & Ligase activity \\
\hline LOC111888402 & GO:0004364 & Glutathione transferase activity \\
\hline LOC111888402 & GO:0005737 & Cytoplasm \\
\hline LOC111888833 & GO:0004553 & Hydrolase activity, hydrolyzing O-glycosyl compounds \\
\hline LOC111888833 & GO:0005576 & Extracellular region \\
\hline LOC111888833 & GO:0009501 & Amyloplast \\
\hline LOC111888833 & GO:0042631 & Cellular response to water deprivation \\
\hline LOC111888833 & GO:0005618 & Cell wall \\
\hline LOC111888833 & GO:0006032 & Chitin catabolic process \\
\hline LOC111888833 & GO:0016021 & Integral component of membrane \\
\hline LOC111888833 & GO:0009651 & Response to salt stress \\
\hline LOC111888833 & GO:0004672 & Protein kinase activity \\
\hline LOC111888833 & GO:0005524 & ATP binding \\
\hline LOC111888833 & GO:0002221 & Pattern recognition receptor signaling pathway \\
\hline LOC111888833 & GO:0009409 & Response to cold \\
\hline LOC111888833 & GO:0009611 & Response to wounding \\
\hline LOC111888833 & GO:0009845 & Seed germination \\
\hline LOC111888833 & GO:0006633 & Fatty acid biosynthetic process \\
\hline LOC111888833 & GO:0006468 & Protein phosphorylation \\
\hline LOC111889457 & GO:0004864 & Protein phosphatase inhibitor activity \\
\hline LOC111889457 & GO:0032515 & Negative regulation of phosphoprotein phosphatase activity \\
\hline LOC111889614 & GO:0016021 & Integral component of membrane \\
\hline LOC111889708 & GO:0019953 & Sexual reproduction \\
\hline LOC111889708 & GO:0005576 & Extracellular region \\
\hline LOC111889708 & GO:0003676 & Nucleic acid binding \\
\hline LOC111889708 & GO:0009505 & Plant-type cell wall \\
\hline LOC111889708 & GO:0009506 & Plasmodesma \\
\hline LOC111889708 & GO:0015074 & DNA integration \\
\hline LOC111889708 & GO:0005794 & Golgi apparatus \\
\hline LOC111889708 & GO:0016021 & Integral component of membrane \\
\hline LOC111890174 & GO:0000786 & Nucleosome \\
\hline LOC111890174 & GO:0046982 & Protein heterodimerization activity \\
\hline LOC111890174 & GO:0010274 & Hydrotropism \\
\hline LOC111890174 & GO:0003677 & DNA binding \\
\hline LOC111890174 & GO:0032259 & Methylation \\
\hline LOC111890174 & GO:0016310 & Phosphorylation \\
\hline LOC111890174 & GO:0005634 & Nucleus \\
\hline LOC111890174 & GO:0016301 & Kinase activity \\
\hline LOC111890174 & GO:0008168 & Methyltransferase activity \\
\hline LOC111890174 & GO:0010369 & Chromocenter \\
\hline LOC111890174 & GO:0016021 & Integral component of membrane \\
\hline LOC111890186 & GO:0031408 & Oxylipin biosynthetic process \\
\hline
\end{tabular}


Supplemental Table 2. (Continued)

\begin{tabular}{|c|c|c|}
\hline Unique identifier & ID & GO term \\
\hline LOC111890186 & GO:0046872 & Metal ion binding \\
\hline LOC111890404 & GO:0006869 & Lipid transport \\
\hline LOC111890404 & GO:0008289 & Lipid binding \\
\hline LOC111890855 & GO:0000325 & Plant-type vacuole \\
\hline LOC111890855 & GO:0042626 & ATPase-coupled transmembrane transporter activity \\
\hline LOC111890855 & GO:0055085 & Transmembrane transport \\
\hline LOC111890855 & GO:0005524 & ATP binding \\
\hline LOC111890855 & GO:0016021 & Integral component of membrane \\
\hline LOC111890880 & GO:0042555 & MCM complex \\
\hline LOC111890880 & GO:0006270 & DNA replication initiation \\
\hline LOC111890880 & GO:0003678 & DNA helicase activity \\
\hline LOC111890880 & GO:0005634 & Nucleus \\
\hline LOC111890880 & GO:1902299 & Pre-replicative complex assembly involved in cell cycle DNA replication \\
\hline LOC111890880 & GO:0000727 & Double-strand break repair via break-induced replication \\
\hline LOC111890880 & GO:1902969 & Mitotic DNA replication \\
\hline LOC111890880 & GO:0006271 & DNA strand elongation involved in DNA replication \\
\hline LOC111890880 & GO:0004315 & 3-oxoacyl-[acyl-carrier-protein] synthase activity \\
\hline LOC111890880 & GO:0006633 & Fatty acid biosynthetic process \\
\hline LOC111890944 & GO:0005524 & ATP binding \\
\hline LOC111890944 & GO:0005829 & Cytosol \\
\hline LOC111890944 & GO:0005634 & Nucleus \\
\hline LOC111890944 & GO:0005788 & Endoplasmic reticulum lumen \\
\hline LOC111890944 & GO:0016021 & Integral component of membrane \\
\hline LOC111891175 & GO:0071944 & Cell periphery \\
\hline LOC111891175 & GO:0016020 & Membrane \\
\hline LOC111891175 & GO:0016829 & Lyase activity \\
\hline LOC111891175 & GO:0006401 & RNA catabolic process \\
\hline LOC111891175 & GO:0003723 & RNA binding \\
\hline LOC111891175 & GO:0009718 & Anthocyanin-containing compound biosynthetic process \\
\hline LOC111891175 & GO:0016036 & Cellular response to phosphate starvation \\
\hline LOC111891175 & GO:0009611 & Response to wounding \\
\hline LOC111891175 & GO:0009867 & Jasmonic acid mediated signaling pathway \\
\hline LOC111891273 & GO:0006817 & Phosphate ion transport \\
\hline LOC111891273 & GO:0022857 & Transmembrane transporter activity \\
\hline LOC111891273 & GO:0005886 & Plasma membrane \\
\hline LOC111891273 & GO:0016021 & Integral component of membrane \\
\hline LOC111891273 & GO:0055085 & Transmembrane transport \\
\hline LOC111891273 & GO:0006857 & Oligopeptide transport \\
\hline LOC111891273 & GO:0015706 & Nitrate transport \\
\hline LOC111891273 & GO:0010167 & Response to nitrate \\
\hline LOC111891616 & GO:0015267 & Channel activity \\
\hline LOC111891616 & GO:0006833 & Water transport \\
\hline LOC111891616 & GO:0016021 & Integral component of membrane \\
\hline LOC111891616 & GO:0055085 & Transmembrane transport \\
\hline
\end{tabular}


Supplemental Table 2. (Continued)

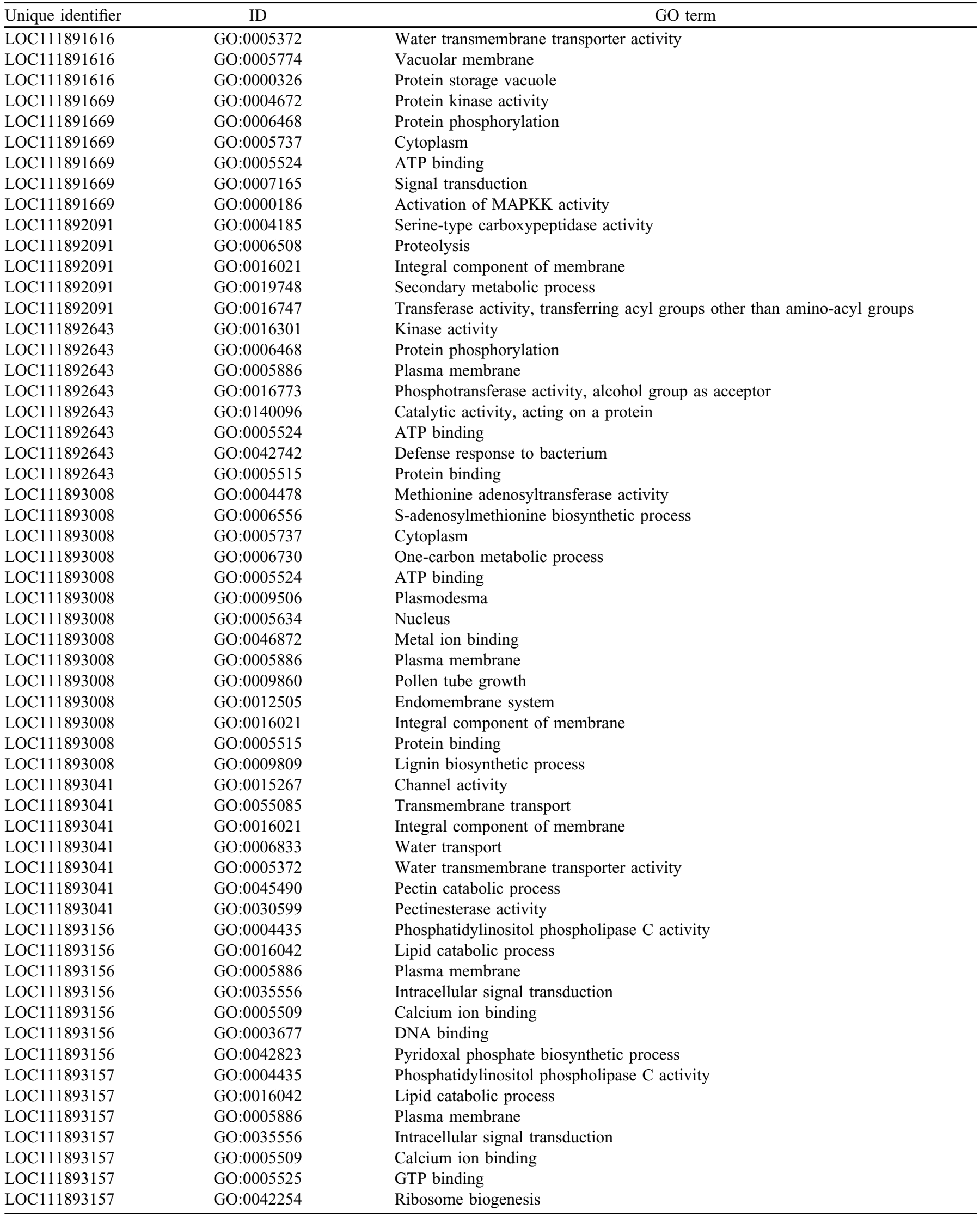


Supplemental Table 2. (Continued)

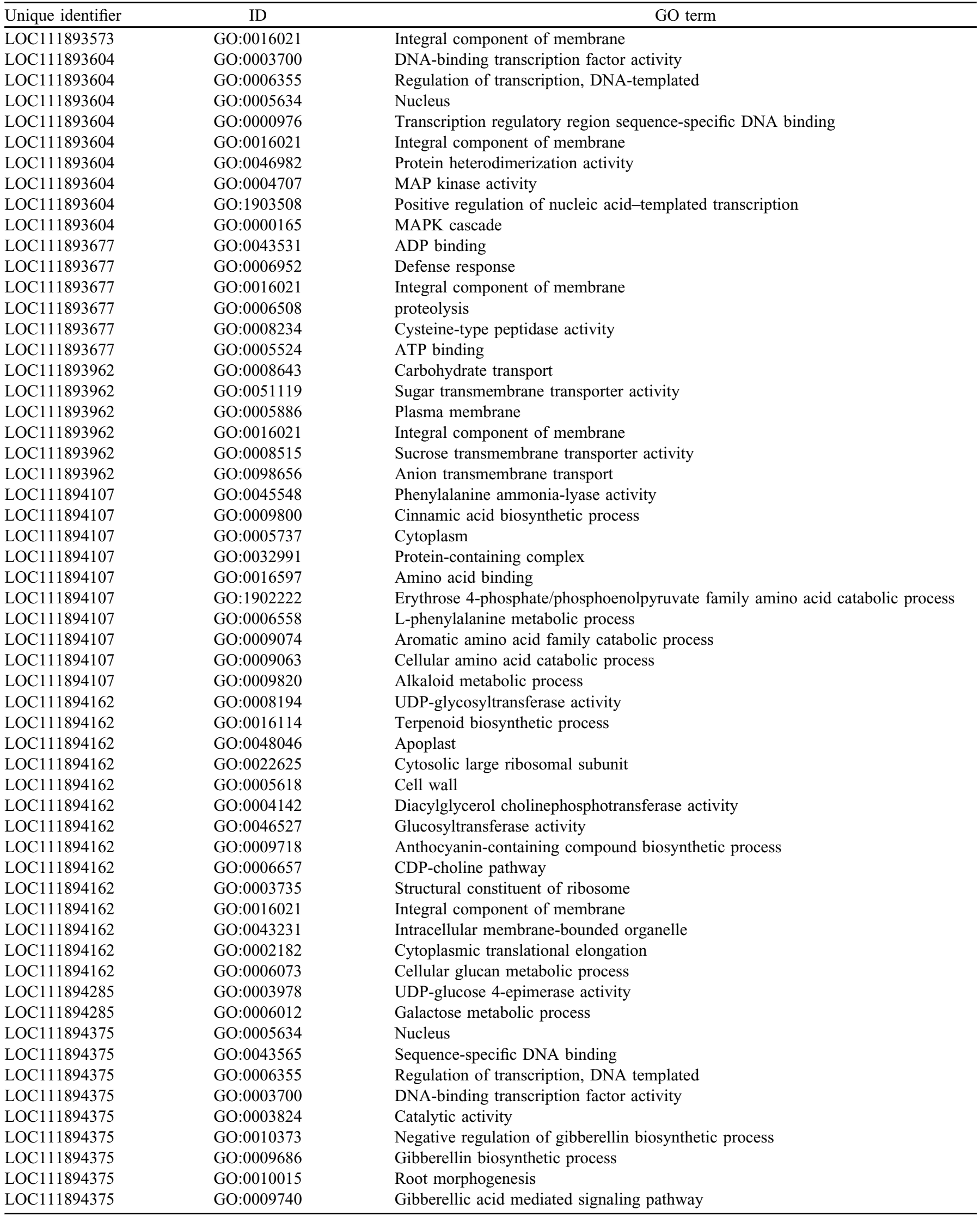


Supplemental Table 2. (Continued)

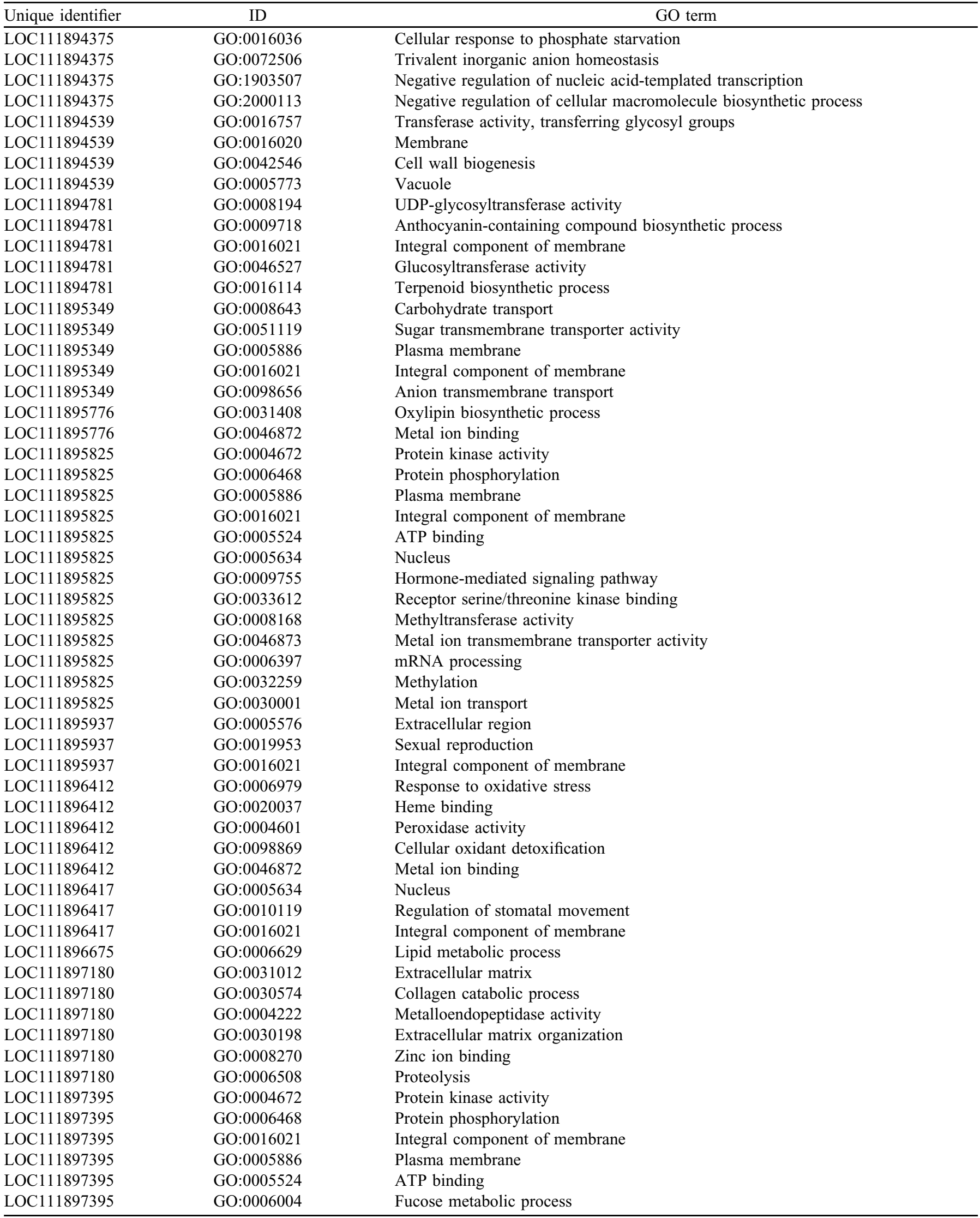


Supplemental Table 2. (Continued)

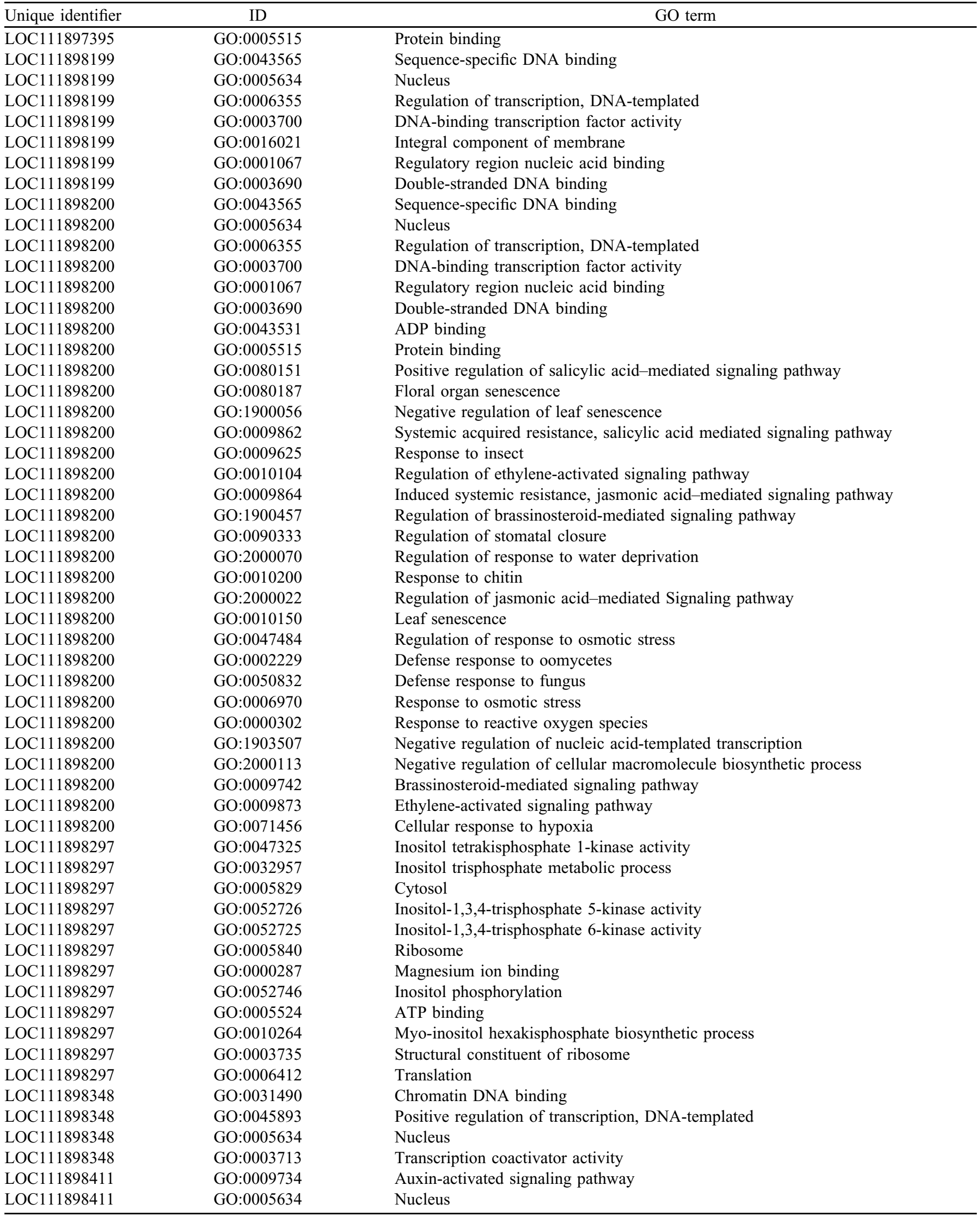


Supplemental Table 2. (Continued)

\begin{tabular}{|c|c|c|}
\hline Unique identifier & ID & GO term \\
\hline$\overline{L O C} 111898411$ & GO:0003830 & Beta-1,4-mannosylglycoprotein 4-beta-N-acetylglucosaminyltransferase activity \\
\hline LOC111898411 & GO:0016020 & Membrane \\
\hline LOC111898411 & GO:0006355 & Regulation of transcription, DNA-templated \\
\hline LOC111898411 & GO:0010218 & Response to far red light \\
\hline LOC111898411 & GO:0010114 & Response to red light \\
\hline LOC111898411 & GO:0006487 & Protein N-linked glycosylation \\
\hline LOC111898411 & GO:0009736 & Cytokinin-activated signaling pathway \\
\hline LOC111898411 & GO:0018215 & Protein phosphopantetheinylation \\
\hline LOC111898411 & GO:0000160 & Phosphorelay signal transduction system \\
\hline LOC111898508 & GO:0008194 & UDP-glycosyltransferase activity \\
\hline LOC111898611 & GO:0042026 & Protein refolding \\
\hline LOC111898611 & GO:0005524 & ATP binding \\
\hline LOC111898611 & GO:0009570 & Chloroplast stroma \\
\hline LOC111898611 & GO:0051085 & Chaperone cofactor-dependent protein refolding \\
\hline LOC111898611 & GO:0022626 & Cytosolic ribosome \\
\hline LOC111898626 & GO:0008194 & UDP-glycosyltransferase activity \\
\hline LOC111898626 & GO:0009718 & Anthocyanin-containing compound biosynthetic process \\
\hline LOC111898626 & GO:0046527 & Glucosyltransferase activity \\
\hline LOC111898626 & GO:0019761 & Glucosinolate biosynthetic process \\
\hline LOC111898626 & GO:0052544 & Defense response by callose deposition in cell wall \\
\hline LOC111898626 & GO:0042742 & Defense response to bacterium \\
\hline LOC111898732 & GO:0046872 & Metal ion binding \\
\hline LOC111898732 & GO:0016567 & Protein ubiquitination \\
\hline LOC111898732 & GO:0005634 & Nucleus \\
\hline LOC111898732 & GO:0005516 & Calmodulin binding \\
\hline LOC111898732 & GO:0005737 & Cytoplasm \\
\hline LOC111898732 & GO:0009751 & Response to salicylic acid \\
\hline LOC111898732 & GO:0009553 & ERmbryo sac development \\
\hline LOC111898732 & GO:0009555 & Pollen development \\
\hline LOC111898732 & GO:0042542 & Response to hydrogen peroxide \\
\hline LOC111898732 & GO:0009733 & Response to auxin \\
\hline LOC111898732 & GO:0006355 & Regulation of transcription, DNA-templated \\
\hline LOC111899032 & GO:0004197 & Cysteine-type endopeptidase activity \\
\hline LOC111899032 & GO:0006508 & Proteolysis \\
\hline LOC111899252 & GO:0010333 & Terpene synthase activity \\
\hline LOC111899252 & GO:0006720 & Isoprenoid metabolic process \\
\hline LOC111899252 & GO:0005737 & Cytoplasm \\
\hline LOC111899252 & GO:0000287 & Magnesium ion binding \\
\hline LOC111899252 & GO:0008610 & Lipid biosynthetic process \\
\hline LOC111899252 & GO:0102698 & 5-epi-aristolochene synthase activity \\
\hline LOC111899252 & GO:0120252 & Hydrocarbon metabolic process \\
\hline LOC111899252 & GO:0006952 & Defense response \\
\hline LOC111899252 & GO:0009975 & Cyclase activity \\
\hline LOC111899252 & GO:0044249 & Cellular biosynthetic process \\
\hline LOC111899252 & GO:0052682 & Epi-cedrol synthase activity \\
\hline LOC111899252 & GO:0009739 & Eesponse to gibberellin \\
\hline LOC111899252 & GO:0000302 & Eesponse to reactive oxygen species \\
\hline LOC111899324 & GO:0004805 & Trehalose-phosphatase activity \\
\hline LOC111899324 & GO:0005992 & Trehalose biosynthetic process \\
\hline LOC111899324 & GO:0016021 & Integral component of membrane \\
\hline LOC111899324 & GO:0005829 & Cytosol \\
\hline LOC111899324 & GO:0009507 & Chloroplast \\
\hline LOC111899324 & GO:0016311 & Dephosphorylation \\
\hline LOC111899324 & GO:0015927 & Trehalase activity \\
\hline LOC111899324 & GO:0005634 & Nucleus \\
\hline LOC111899324 & GO:0009651 & Response to salt stress \\
\hline LOC111899324 & GO:0006979 & Response to oxidative stress \\
\hline
\end{tabular}


Supplemental Table 2. (Continued)

\begin{tabular}{|c|c|c|}
\hline Unique identifier & ID & GO term \\
\hline LOC111899382 & GO:0042973 & Glucan endo-1,3-beta-D-glucosidase activity \\
\hline LOC111899382 & GO:0006952 & Defense response \\
\hline LOC111899382 & GO:0046658 & Anchored component of plasma membrane \\
\hline LOC111899382 & GO:0005975 & Carbohydrate metabolic process \\
\hline LOC111899806 & GO:0090376 & Seed trichome differentiation \\
\hline LOC111899806 & GO:0016021 & Integral component of membrane \\
\hline LOC111899806 & GO:0009735 & Response to cytokinin \\
\hline LOC111899806 & GO:0005576 & Extracellular region \\
\hline LOC111899806 & GO:0009739 & Response to gibberellin \\
\hline LOC111899806 & GO:0009651 & Response to salt stress \\
\hline LOC111899806 & GO:0009737 & Response to abscisic acid \\
\hline LOC111899806 & GO:0009733 & Response to auxin \\
\hline LOC111899806 & GO:0007155 & Cell adhesion \\
\hline LOC111900059 & GO:0016787 & Hydrolase activity \\
\hline LOC111900135 & GO:0005524 & ATP binding \\
\hline LOC111900135 & GO:0016021 & Integral component of membrane \\
\hline LOC111900177 & GO:0016042 & Lipid catabolic process \\
\hline LOC111900177 & GO:0045735 & Nutrient reservoir activity \\
\hline LOC111900177 & GO:0005773 & Vacuole \\
\hline LOC111900177 & GO:0016787 & Hydrolase activity \\
\hline LOC111900177 & GO:0016740 & Transferase activity \\
\hline LOC111900177 & GO:0016021 & Integral component of membrane \\
\hline LOC111900246 & GO:0016984 & Ribulose-bisphosphate carboxylase activity \\
\hline LOC111900246 & GO:0009853 & Photorespiration \\
\hline LOC111900246 & GO:0015979 & Photosynthesis \\
\hline LOC111900275 & GO:0030001 & Metal ion transport \\
\hline LOC111900275 & GO:0046872 & Metal ion binding \\
\hline LOC111900275 & GO:0016020 & Membrane \\
\hline LOC111900275 & GO:0055073 & Cadmium ion homeostasis \\
\hline LOC111900275 & GO:0071585 & Detoxification of cadmium ion \\
\hline LOC111900788 & GO:0031225 & Anchored component of membrane \\
\hline LOC111900788 & GO:0016021 & Integral component of membrane \\
\hline LOC111900976 & GO:0004185 & Serine-type carboxypeptidase activity \\
\hline LOC111900976 & GO:0019748 & Secondary metabolic process \\
\hline LOC111900976 & GO:0005576 & Extracellular region \\
\hline LOC111900976 & GO:0006508 & Proteolysis \\
\hline LOC111900976 & GO:0016021 & Integral component of membrane \\
\hline LOC111900976 & GO:0016747 & Transferase activity, transferring acyl groups other than amino-acyl groups \\
\hline LOC111901004 & GO:0010333 & Terpene synthase activity \\
\hline LOC111901004 & GO:0016102 & Diterpenoid biosynthetic process \\
\hline LOC111901004 & GO:0009536 & Plastid \\
\hline LOC111901004 & GO:0000287 & Magnesium ion binding \\
\hline LOC111901004 & GO:0016021 & Integral component of membrane \\
\hline LOC111901004 & GO:0080027 & Response to herbivore \\
\hline LOC111901004 & GO:0000304 & Response to singlet oxygen \\
\hline LOC111901004 & GO:0080013 & (E,E)-geranyllinalool synthase activity \\
\hline LOC111901004 & GO:0009753 & Response to jasmonic acid \\
\hline LOC111901004 & GO:0050554 & Abietadiene synthase activity \\
\hline LOC111901004 & GO:0009611 & Response to wounding \\
\hline LOC111901004 & GO:0009617 & Response to bacterium \\
\hline LOC111901011 & GO:0005634 & Nucleus \\
\hline LOC111901011 & GO:0043565 & Sequence-specific DNA binding \\
\hline LOC111901011 & GO:0006355 & Regulation of transcription, DNA-templated \\
\hline LOC111901011 & GO:0003700 & DNA-binding transcription factor activity \\
\hline LOC111901019 & GO:0005509 & Calcium ion binding \\
\hline LOC111901426 & GO:0047769 & Arogenate dehydratase activity \\
\hline LOC111901426 & GO:0009570 & Chloroplast stroma \\
\hline
\end{tabular}


Supplemental Table 2. (Continued)

\begin{tabular}{|c|c|c|}
\hline Unique identifier & ID & GO term \\
\hline LOC111901426 & GO:1902223 & Erythrose 4-phosphate/phosphoenolpyruvate family amino acid biosynthetic process \\
\hline LOC111901426 & GO:0009095 & Aromatic amino acid family biosynthetic process, prephenate pathway \\
\hline LOC111901426 & GO:0004106 & Chorismate mutase activity \\
\hline LOC111901426 & GO:0008652 & Cellular amino acid biosynthetic process \\
\hline LOC111901426 & GO:0016021 & Integral component of membrane \\
\hline LOC111901838 & GO:0005634 & Nucleus \\
\hline LOC111901838 & GO:0006355 & Regulation of transcription, DNA-templated \\
\hline LOC111901838 & GO:0005737 & Cytoplasm \\
\hline LOC111901841 & GO:0046423 & Allene-oxide cyclase activity \\
\hline LOC111901841 & GO:0009695 & Jasmonic acid biosynthetic process \\
\hline LOC111901841 & GO:0009507 & Chloroplast \\
\hline LOC111901841 & GO:1900367 & Positive regulation of defense response to insect \\
\hline LOC111901841 & GO:0080186 & Developmental vegetative growth \\
\hline LOC111901841 & GO:0009625 & Response to insect \\
\hline LOC111901841 & GO:0009864 & Induced systemic resistance, jasmonic acid-mediated signaling pathway \\
\hline LOC111901841 & GO:0010218 & Response to far red light \\
\hline LOC111901841 & GO:0009646 & Response to absence of light \\
\hline LOC111901841 & GO:0010114 & Response to red light \\
\hline LOC111901841 & GO:0048573 & Photoperiodism, flowering \\
\hline LOC111901841 & GO:0009751 & Response to salicylic acid \\
\hline LOC111901841 & GO:0009723 & Response to ethylene \\
\hline LOC111901841 & GO:0042542 & Response to hydrogen peroxide \\
\hline LOC111901841 & GO:0009611 & Response to wounding \\
\hline LOC111901841 & GO:0010038 & Response to metal ion \\
\hline LOC111902058 & GO:0004553 & Hydrolase activity, hydrolyzing O-glycosyl compounds \\
\hline LOC111902058 & GO:0005576 & Extracellular region \\
\hline LOC111902058 & GO:0031222 & Arabinan catabolic process \\
\hline LOC111902058 & GO:0009505 & Plant-type cell wall \\
\hline LOC111902058 & GO:0045493 & Xylan catabolic process \\
\hline LOC111902058 & GO:0016021 & Integral component of membrane \\
\hline LOC111902216 & GO:0009664 & Plant-type cell wall organization \\
\hline LOC111902216 & GO:0005618 & Cell wall \\
\hline LOC111902216 & GO:0005576 & Extracellular region \\
\hline LOC111902216 & GO:0016020 & Membrane \\
\hline LOC111902216 & GO:0006949 & Syncytium formation \\
\hline LOC111902319 & GO:0016874 & Ligase activity \\
\hline LOC111903004 & GO:0008171 & O-methyltransferase activity \\
\hline LOC111903004 & GO:0032259 & Methylation \\
\hline LOC111903004 & GO:0016021 & Integral component of membrane \\
\hline LOC111903004 & GO:0019438 & Aromatic compound biosynthetic process \\
\hline LOC111903004 & GO:0046983 & Protein dimerization activity \\
\hline LOC111903004 & GO:0008757 & S-adenosylmethionine-dependent methyltransferase activity \\
\hline LOC111903226 & GO:0042910 & Xenobiotic transmembrane transporter activity \\
\hline
\end{tabular}


Supplemental Table 2. (Continued)

\begin{tabular}{|c|c|c|}
\hline Unique identifier & ID & GO term \\
\hline LOC111903226 & GO:0042908 & Xenobiotic transport \\
\hline LOC111903226 & GO:0016021 & Integral component of membrane \\
\hline LOC111903226 & GO:0015297 & Antiporter activity \\
\hline LOC111903232 & GO:0003700 & DNA-binding transcription factor activity \\
\hline LOC111903232 & GO:0005634 & Nucleus \\
\hline LOC111903232 & GO:0006355 & Regulation of transcription, DNA-templated \\
\hline LOC111903232 & GO:0001067 & Regulatory region nucleic acid binding \\
\hline LOC111903232 & GO:0009873 & Ethylene-activated signaling pathway \\
\hline LOC111903232 & GO:0006952 & Defense response \\
\hline LOC111903232 & GO:0019757 & glycosinolate metabolic process \\
\hline LOC111903232 & GO:0016143 & S-glycoside metabolic process \\
\hline LOC111903232 & GO:0009620 & Response to fungus \\
\hline LOC111903507 & GO:0005737 & Cytoplasm \\
\hline LOC111903572 & GO:0010333 & Terpene synthase activity \\
\hline LOC111903572 & GO:0033383 & Geranyl diphosphate metabolic process \\
\hline LOC111903572 & GO:0009536 & plastid \\
\hline LOC111903572 & GO:0016114 & Terpenoid biosynthetic process \\
\hline LOC111903572 & GO:0000287 & Magnesium ion binding \\
\hline LOC111903572 & GO:0009611 & Response to wounding \\
\hline LOC111903572 & GO:0034008 & R-linalool synthase activity \\
\hline LOC111903572 & GO:1901941 & $(+)$-epi-alpha-bisabolol metabolic process \\
\hline LOC111903572 & GO:0045339 & Farnesyl diphosphate catabolic process \\
\hline LOC111903849 & GO:0003700 & DNA-binding transcription factor activity \\
\hline LOC111903849 & GO:0009908 & Flower development \\
\hline LOC111903849 & GO:0042127 & Regulation of cell population proliferation \\
\hline LOC111903849 & GO:0030154 & Cell differentiation \\
\hline LOC111903849 & GO:1901564 & Organonitrogen compound metabolic process \\
\hline LOC111903871 & GO:0004672 & Protein kinase activity \\
\hline LOC111903871 & GO:0006468 & Protein phosphorylation \\
\hline LOC111903871 & GO:0005829 & Cytosol \\
\hline LOC111903871 & GO:0005524 & ATP binding \\
\hline LOC111903871 & GO:0071456 & Cellular response to hypoxia \\
\hline LOC111903871 & GO:0009658 & Chloroplast organization \\
\hline LOC111903871 & GO:0009737 & Response to abscisic acid \\
\hline LOC111904177 & GO:0005773 & Vacuole \\
\hline LOC111904177 & GO:0015031 & Protein transport \\
\hline LOC111904177 & GO:0061630 & Ubiquitin protein ligase activity \\
\hline LOC111904177 & GO:0016021 & Integral component of membrane \\
\hline LOC111904177 & GO:0030170 & Pyridoxal phosphate binding \\
\hline LOC111904177 & GO:0005515 & Protein binding \\
\hline LOC111904177 & GO:0022857 & Transmembrane transporter activity \\
\hline LOC111904177 & GO:0006511 & Ubiquitin-dependent protein catabolic process \\
\hline LOC111904177 & GO:0046872 & Metal ion binding \\
\hline LOC111904177 & GO:0016567 & Protein ubiquitination \\
\hline
\end{tabular}


Supplemental Table 2. (Continued)

\begin{tabular}{|c|c|c|}
\hline Unique identifier & ID & GO term \\
\hline LOC111904177 & GO:0000139 & Golgi membrane \\
\hline LOC111904177 & GO:0006817 & Phosphate ion transport \\
\hline LOC111904236 & GO:0004185 & Serine-type carboxypeptidase activity \\
\hline LOC111904236 & GO:0006508 & Proteolysis \\
\hline LOC111904561 & GO:0016757 & Transferase activity, transferring glycosyl groups \\
\hline LOC111904561 & GO:0090406 & Pollen tube \\
\hline LOC111904561 & GO:0016021 & Integral component of membrane \\
\hline LOC111905143 & GO:0008194 & UDP-glycosyltransferase activity \\
\hline LOC111905143 & GO:0009718 & Anthocyanin-containing compound biosynthetic process \\
\hline LOC111905143 & GO:0016021 & Integral component of membrane \\
\hline LOC111905143 & GO:0046527 & Glucosyltransferase activity \\
\hline LOC111905147 & GO:0004013 & Adenosylhomocysteinase activity \\
\hline LOC111905147 & GO:0006730 & One-carbon metabolic process \\
\hline LOC111905147 & GO:0005829 & Cytosol \\
\hline LOC111905147 & GO:0033353 & S-adenosylmethionine cycle \\
\hline LOC111905147 & GO:0005773 & Vacuole \\
\hline LOC111905147 & GO:0009506 & Plasmodesma \\
\hline LOC111905147 & GO:0003729 & mRNA binding \\
\hline LOC111905147 & GO:0006346 & DNA methylation-dependent heterochromatin assembly \\
\hline LOC111905147 & GO:0005507 & Copper ion binding \\
\hline LOC111905147 & GO:0005515 & Protein binding \\
\hline LOC111876248 & GO:0046873 & Metal ion binding \\
\hline LOC111876518 & GO:0015699 & Inorganic anion transport \\
\hline LOC111876729 & GO:0003888 & DNA-directed DNA polymerase activity \\
\hline LOC111876729 & GO:0071898 & DNA biosynthetic process \\
\hline LOC111876729 & GO:0005635 & Nucleus \\
\hline LOC111876729 & GO:0006261 & DNA replication \\
\hline LOC111876729 & GO:0051540 & 5 iron, 4 sulfur cluster binding \\
\hline LOC111876729 & GO:0022617 & DNA strand elongation \\
\hline LOC111876729 & GO:0019104 & Pyrimidine nucleotide binding \\
\hline LOC111876729 & GO:0000429 & DNA-directed RNA polymerase complex \\
\hline LOC111876729 & GO:0003678 & DNA binding \\
\hline LOC111876729 & GO:0003897 & DNA primase activity \\
\hline LOC111876729 & GO:0030895 & Replisome \\
\hline LOC111876729 & GO:0042576 & DNA polymerase complex \\
\hline LOC111876729 & GO:0046873 & Metal ion binding \\
\hline LOC111876729 & GO:0003683 & Chromatin binding \\
\hline LOC111876729 & GO:0070014 & Intracellular organelle lumen \\
\hline LOC111876729 & GO:0043234 & Organelle lumen \\
\hline LOC111876729 & GO:0009966 & Leaf morphogenesis \\
\hline LOC111876729 & GO: 1903048 & Mitotic cell cycle process \\
\hline LOC111876729 & GO:0017077 & Purine nucleotide binding \\
\hline LOC111876729 & GO:0032775 & RNA biosynthetic process \\
\hline
\end{tabular}


Supplemental Table 2. (Continued)

\begin{tabular}{|c|c|c|}
\hline Unique identifier & ID & GO term \\
\hline LOC111876788 & GO:0016882 & Acid-amino acid ligase activity \\
\hline LOC111876788 & GO:0102058 & Jasmonoyl-valine synthetase activity \\
\hline LOC111876788 & GO:0102059 & Jasmonoyl-leucine synthetase activity \\
\hline LOC111877040 & GO:0031013 & Extracellular matrix \\
\hline LOC111877040 & GO:0030575 & Collagen catabolic process \\
\hline LOC 111877040 & GO:0030199 & Extracellular matrix organization \\
\hline LOC111877040 & GO:0008271 & Zinc ion binding \\
\hline LOC111877040 & GO:0006509 & Proteolysis \\
\hline LOC111877142 & GO:0016788 & Hydrolase activity \\
\hline LOC111877486 & GO:0005508 & Copper ion binding \\
\hline LOC111877486 & GO:0030002 & Metal ion transport \\
\hline LOC111877486 & GO:0072512 & Divalent inorganic cation transport \\
\hline LOC111877486 & GO:0005525 & ATP binding \\
\hline LOC111877831 & GO:0016788 & Hydrolase activity \\
\hline LOC111877831 & GO:0043532 & ADP binding \\
\hline LOC111879317 & GO:0009507 & Plasmodesma \\
\hline LOC111879317 & GO:0046778 & Protein autophosphorylation \\
\hline LOC111879317 & GO:0004673 & Protein kinase activity \\
\hline LOC111879317 & GO:0005887 & Plasma membrane \\
\hline LOC111879317 & GO:0005525 & ATP binding \\
\hline LOC111879317 & GO:0016022 & Integral component of membrane \\
\hline LOC111879317 & GO:0005510 & Calcium ion binding \\
\hline LOC111879404 & GO:0039695 & Viral RNA genome replication \\
\hline LOC111879404 & GO:0098589 & Bounding membrane of organelle \\
\hline LOC111879404 & GO:0031985 & Organelle subcompartment \\
\hline LOC111879404 & GO:0012506 & Endomembrane system \\
\hline LOC111879404 & GO:0016022 & Integral component of membrane \\
\hline LOC111879404 & GO:0043232 & Intracellular membrane-bounded organelle \\
\hline LOC111879404 & GO:0005887 & Plasma membrane \\
\hline LOC111880354 & GO:0016788 & Hydrolase activity \\
\hline LOC111880354 & GO:0016022 & Integral component of membrane \\
\hline LOC111880882 & GO:0010092 & Trichome branching \\
\hline LOC111880980 & GO:0046984 & Protein dimerization activity \\
\hline LOC 111880980 & GO:0005635 & Nucleus \\
\hline LOC111880980 & GO:0003724 & RNA binding \\
\hline LOC111880980 & GO:0016022 & Integral component of membrane \\
\hline LOC111881023 & GO:0106312 & NA \\
\hline LOC111881023 & GO:0006469 & Protein phosphorylation \\
\hline LOC111881023 & GO:0005887 & Plasma membrane \\
\hline LOC111881023 & GO:0106311 & NA \\
\hline LOC111881023 & GO:0030247 & Carbohydrate binding \\
\hline LOC111881023 & GO:0016022 & Integral component of membrane \\
\hline LOC111881023 & GO:0005525 & ATP binding \\
\hline
\end{tabular}


Supplemental Table 2. (Continued)

\begin{tabular}{|c|c|c|}
\hline Unique identifier & ID & GO term \\
\hline$\overline{L O C 111881483}$ & GO:0006630 & Lipid metabolic process \\
\hline LOC111881483 & GO:0005635 & Nucleus \\
\hline LOC111881483 & GO:0016788 & Hydrolase activity \\
\hline LOC111881493 & GO:0005635 & Nucleus \\
\hline LOC111881493 & GO:0080031 & Methyl indole-3-acetate esterase activity \\
\hline LOC111881493 & GO:0009821 & Alkaloid metabolic process \\
\hline LOC111881555 & GO:0004673 & Protein kinase activity \\
\hline LOC111881555 & GO:0006469 & Protein phosphorylation \\
\hline LOC111881555 & GO:0016022 & Integral component of membrane \\
\hline LOC111881555 & GO:0005887 & Plasma membrane \\
\hline LOC111881555 & GO:0005525 & ATP binding \\
\hline LOC111881555 & GO:0005526 & GTP binding \\
\hline LOC111881703 & GO:0005841 & Ribosome \\
\hline LOC111881936 & GO:0009508 & Chloroplast \\
\hline LOC111881936 & GO:0015980 & Photosynthesis \\
\hline LOC111881936 & GO:0046873 & Metal ion binding \\
\hline LOC111881936 & GO:0071492 & Cellular response to red light \\
\hline LOC111881936 & GO:0009580 & Thylakoid \\
\hline LOC111881936 & GO:0071491 & Cellular response to far red light \\
\hline LOC111881936 & GO:0010118 & Photoprotection \\
\hline LOC111881936 & GO:0071487 & Cellular response to high light intensity \\
\hline LOC111881936 & GO:0010031 & Positive regulation of seed germination \\
\hline LOC111881936 & GO:0071493 & Cellular response to ultraviolet-A \\
\hline LOC111881936 & GO:0009410 & Eesponse to cold \\
\hline LOC111881936 & GO:0010225 & Response to ultraviolet-B \\
\hline LOC111881938 & GO:0009508 & Chloroplast \\
\hline LOC111881938 & GO:0015980 & Photosynthesis \\
\hline LOC111881938 & GO:0046873 & Metal ion binding \\
\hline LOC111881938 & GO:0071492 & Cellular response to red light \\
\hline LOC111881938 & GO:0009580 & Thylakoid \\
\hline LOC111881938 & GO:0071491 & Cellular response to far red light \\
\hline LOC111881938 & GO:0010118 & Photoprotection \\
\hline LOC111881938 & GO:0071487 & Cellular response to high light intensity \\
\hline LOC111881938 & GO:0010031 & Positive regulation of seed germination \\
\hline LOC111881938 & GO:0071493 & Cellular response to ultraviolet-A \\
\hline LOC111881938 & GO:0031985 & Organelle subcompartment \\
\hline LOC111881938 & GO:0098797 & Membrane protein complex \\
\hline LOC111881938 & GO:0071484 & Cellular response to blue light \\
\hline LOC111881938 & GO:0010381 & Regulation of chlorophyll biosynthetic process \\
\hline LOC111881938 & GO:0016022 & Integral component of membrane \\
\hline LOC111881938 & GO:0080168 & Response to karrikin \\
\hline LOC111881938 & GO:0034606 & Cellular response to heat \\
\hline LOC111881938 & GO:0009410 & Response to cold \\
\hline LOC111881938 & GO:0010225 & Response to ultraviolet B \\
\hline
\end{tabular}


Supplemental Table 2. (Continued)

\begin{tabular}{|c|c|c|}
\hline Unique identifier & ID & GO term \\
\hline LOC111882124 & GO:0006818 & Phosphate ion transport \\
\hline LOC111882124 & GO:0022858 & Transmembrane transporter activity \\
\hline LOC111882124 & GO:0016022 & Integral component of membrane \\
\hline LOC111882378 & GO:0019954 & Sexual reproduction \\
\hline LOC 111882378 & GO:0005577 & Extracellular region \\
\hline LOC111882480 & GO:0005525 & ATP binding \\
\hline LOC111882485 & GO:0005635 & Nucleus \\
\hline LOC111882485 & GO:0006356 & Regulation of transcription, DNA-templated \\
\hline LOC111882485 & GO:0003678 & DNA binding \\
\hline LOC111882485 & GO:0005516 & Protein binding \\
\hline LOC111882485 & GO:0006953 & Defense response \\
\hline LOC111882485 & GO:0009874 & Ethylene-activated signaling pathway \\
\hline LOC111882589 & GO:0005635 & Nucleus \\
\hline LOC111882589 & GO:0005525 & ATP binding \\
\hline LOC111882589 & GO:0016022 & Integral component of membrane \\
\hline LOC111882589 & GO:0080137 & Priming of cellular response to stress \\
\hline LOC111882589 & GO:0052318 & Camalexin metabolic process \\
\hline LOC111882589 & GO:0009701 & Indole phytoalexin biosynthetic process \\
\hline LOC111882589 & GO:1902066 & Response to L-glutamate \\
\hline LOC111882589 & GO:0005516 & Protein binding \\
\hline LOC111882589 & GO: 1901003 & Positive regulation of response to salt stress \\
\hline LOC111882589 & GO:0022858 & Transmembrane transporter activity \\
\hline LOC111882589 & GO:0010230 & Inflorescence development \\
\hline LOC111882589 & GO:0050833 & Defense response to fungus \\
\hline LOC111882589 & GO:0006971 & Response to osmotic stress \\
\hline LOC111882589 & GO:0009612 & Response to wounding \\
\hline LOC111882589 & GO:0009618 & Response to bacterium \\
\hline LOC111882589 & GO:0006980 & Response to oxidative stress \\
\hline LOC111882589 & GO:0044273 & Sulfur compound biosynthetic process \\
\hline LOC111882589 & GO:0010469 & Regulation of gene expression \\
\hline LOC111882589 & GO:0009627 & Plant-type hypersensitive response \\
\hline LOC111882589 & GO:0009739 & Abscisic acid-activated signaling pathway \\
\hline LOC111882589 & GO:0006858 & Oligopeptide transport \\
\hline LOC111882589 & GO:0055086 & Transmembrane transport \\
\hline LOC111882696 & GO:0016788 & Hydrolase activity \\
\hline LOC111882722 & GO:0005887 & Plasma membrane \\
\hline LOC111882722 & GO:0034155 & Toll-like receptor 7 signaling pathway \\
\hline LOC111882722 & GO:0003728 & Single-stranded RNA binding \\
\hline LOC 111882722 & GO:0002756 & MyD88-dependent toll-like receptor signaling pathway \\
\hline LOC111882722 & GO:0004889 & Transmembrane signaling receptor activity \\
\hline LOC111882722 & GO:0016022 & Integral component of membrane \\
\hline LOC111882722 & GO:0051608 & Defense response to virus \\
\hline LOC111882722 & GO:0006956 & Immune response \\
\hline LOC111882971 & GO:0050291 & Sphingomyelin phosphodiesterase D activity \\
\hline
\end{tabular}


Supplemental Table 2. (Continued)

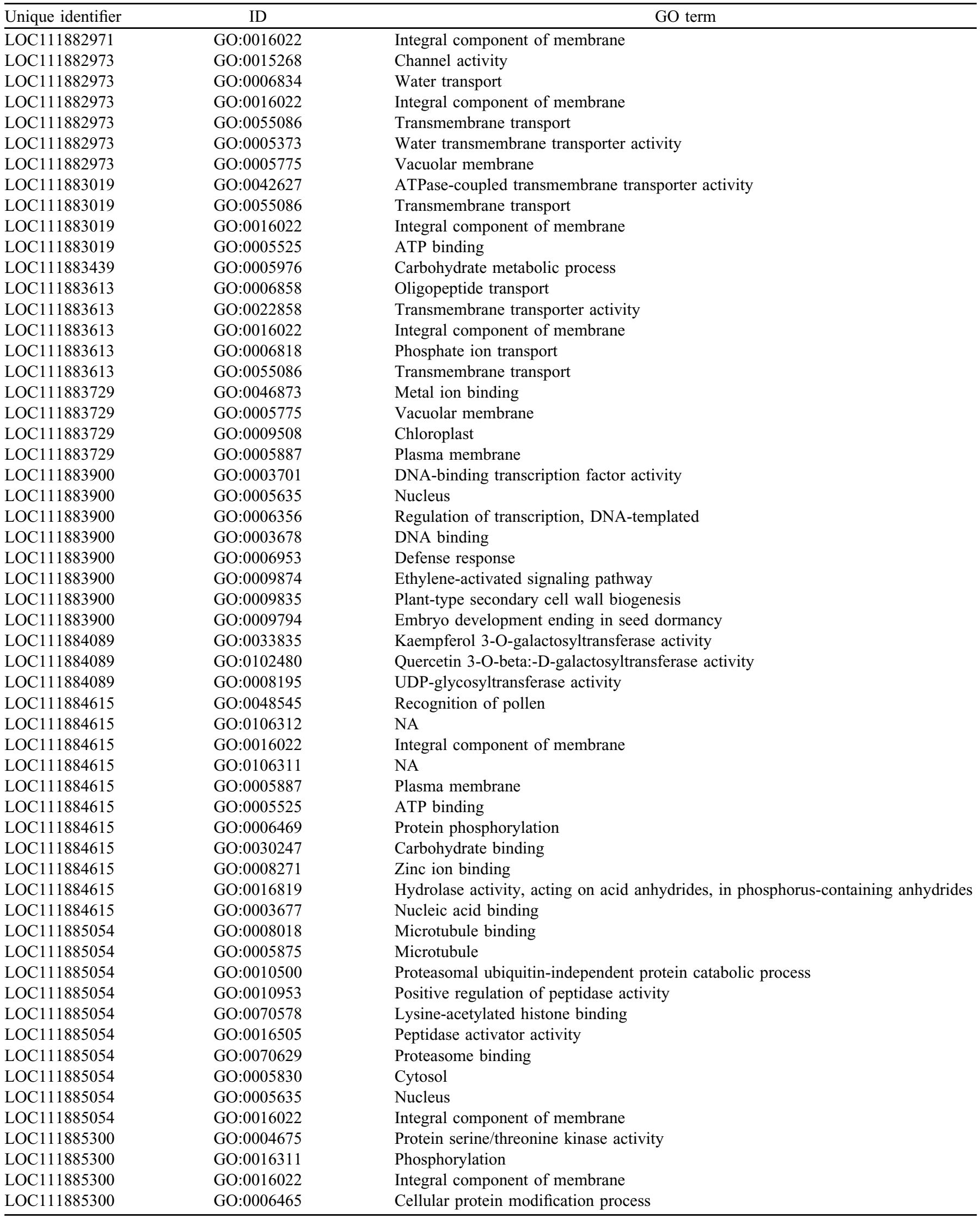


Supplemental Table 2. (Continued)

\begin{tabular}{|c|c|c|}
\hline Unique identifier & ID & GO term \\
\hline LOC111885300 & GO:0005525 & ATP binding \\
\hline LOC111885714 & GO:0042410 & Caffeoyl-CoA O-methyltransferase activity \\
\hline LOC111885714 & GO:0009810 & Lignin biosynthetic process \\
\hline LOC111885714 & GO:0005841 & Ribosome \\
\hline LOC111885714 & GO:0032260 & Methylation \\
\hline LOC111885714 & GO:0080077 & Caffeoyl CoA:S-adenosyl-L-methionine O-methyltransferase activity \\
\hline LOC111885714 & GO:0016780 & Nucleotidyltransferase activity \\
\hline LOC111885714 & GO:0003736 & Structural constituent of ribosome \\
\hline LOC111885714 & GO:0003724 & RNA binding \\
\hline LOC111885714 & GO:0007624 & Circadian rhythm \\
\hline LOC111885714 & GO:0010468 & Gene expression \\
\hline LOC111885714 & GO:0016071 & RNA metabolic process \\
\hline LOC111886219 & GO:0061631 & Ubiquitin protein ligase activity \\
\hline LOC111886219 & GO:0006512 & Ubiquitin-dependent protein catabolic process \\
\hline LOC111886219 & GO:0016568 & Protein ubiquitination \\
\hline LOC111886241 & GO:0003724 & RNA binding \\
\hline LOC111886241 & GO:0016022 & Integral component of membrane \\
\hline LOC111886241 & GO:0003825 & Catalytic activity \\
\hline LOC111886522 & GO:0008234 & Peptidase activity \\
\hline LOC111886522 & GO:0006509 & Proteolysis \\
\hline LOC111886522 & GO:0016888 & ATPase activity \\
\hline LOC111886522 & GO:0005525 & ATP binding \\
\hline LOC111886525 & GO:0008271 & Zinc ion binding \\
\hline LOC111886531 & GO:0003701 & DNA-binding transcription factor activity \\
\hline LOC111886531 & GO:0001068 & Regulatory region nucleic acid binding \\
\hline LOC111886531 & GO:0003691 & Double-stranded DNA binding \\
\hline LOC111886671 & GO:0003736 & Structural constituent of ribosome \\
\hline LOC111886671 & GO:0005841 & Ribosome \\
\hline LOC111886671 & GO:0006413 & Translation \\
\hline LOC111886671 & GO:0005830 & Cytosol \\
\hline LOC111886671 & GO:0000028 & Ribosomal large subunit assembly \\
\hline LOC111886671 & GO:1990905 & Ribonucleoprotein complex \\
\hline LOC111886671 & GO:0016022 & Integral component of membrane \\
\hline LOC111886857 & GO:0016789 & Hydrolase activity, acting on ester bonds \\
\hline LOC111886949 & GO:0043566 & Sequence-specific DNA binding \\
\hline LOC111886949 & GO:0005635 & Nucleus \\
\hline LOC111886949 & GO:0006356 & Regulation of transcription, DNA-templated \\
\hline LOC111886949 & GO:0003701 & DNA-binding transcription factor activity \\
\hline LOC111886949 & GO:0001068 & Regulatory region nucleic acid binding \\
\hline LOC111886949 & GO:0016741 & Transferase activity \\
\hline LOC111886949 & GO:0003691 & Double-stranded DNA binding \\
\hline LOC111886949 & GO:0009652 & Response to salt stress \\
\hline LOC111886949 & GO:0009415 & Response to water deprivation \\
\hline LOC111887205 & GO:0006980 & Response to oxidative stress \\
\hline
\end{tabular}


Supplemental Table 2. (Continued)

\begin{tabular}{|c|c|c|}
\hline Unique identifier & ID & GO term \\
\hline LOC111887205 & GO:0004602 & Peroxidase activity \\
\hline LOC111887205 & GO:0098870 & Cellular oxidant detoxification \\
\hline LOC111887205 & GO:0020038 & Heme binding \\
\hline LOC111887526 & GO:0016888 & ATPase activity \\
\hline LOC 111887526 & GO:0016022 & Integral component of membrane \\
\hline LOC111887526 & GO:0005525 & ATP binding \\
\hline LOC111887624 & GO:0006509 & Proteolysis \\
\hline LOC111887624 & GO:0005577 & Extracellular region \\
\hline LOC111887624 & GO:0016022 & Integral component of membrane \\
\hline LOC111887690 & GO:0016748 & Transferase activity, transferring acyl groups other than amino-acyl groups \\
\hline LOC111887816 & GO:0016043 & Lipid catabolic process \\
\hline LOC111887816 & GO:0045736 & Nutrient reservoir activity \\
\hline LOC111887880 & GO:0048047 & Apoplast \\
\hline LOC111887880 & GO:0042974 & Glucan endo-1,3-beta-D-glucosidase activity \\
\hline LOC111887880 & GO:0005976 & Carbohydrate metabolic process \\
\hline LOC111887880 & GO:0016022 & Integral component of membrane \\
\hline LOC111887880 & GO:0016875 & Ligase activity \\
\hline LOC111887885 & GO:0048047 & Apoplast \\
\hline LOC111887885 & GO:0042974 & Glucan endo-1,3-beta-D-glucosidase activity \\
\hline LOC111887885 & GO:0005976 & Carbohydrate metabolic process \\
\hline LOC111887885 & GO:0016022 & Integral component of membrane \\
\hline LOC111887885 & GO:0016875 & Ligase activity \\
\hline LOC111888403 & GO:0006750 & Glutathione metabolic process \\
\hline LOC111888834 & GO:0005619 & Cell wall \\
\hline LOC111888834 & GO:0006033 & Chitin catabolic process \\
\hline LOC111888834 & GO:0016022 & Integral component of membrane \\
\hline LOC111888834 & GO:0009643 & Response to light intensity \\
\hline LOC111888834 & GO:0061784 & Peptidoglycan muralytic activity \\
\hline LOC111888834 & GO:0004316 & 4-oxoacyl-[acyl-carrier-protein] synthase activity \\
\hline LOC111888834 & GO:0005510 & Calcium ion binding \\
\hline LOC111888834 & GO:0009652 & Response to salt stress \\
\hline LOC111888834 & GO:0004673 & Protein kinase activity \\
\hline LOC111888834 & GO:0005525 & ATP binding \\
\hline LOC111888834 & GO:0002222 & Pattern recognition receptor signaling pathway \\
\hline LOC111888834 & GO:0009410 & Response to cold \\
\hline LOC111888834 & GO:0009612 & Response to wounding \\
\hline LOC111888834 & GO:0009846 & Seed germination \\
\hline LOC111888834 & GO:0006634 & Fatty acid biosynthetic process \\
\hline LOC111888834 & GO:0006469 & Protein phosphorylation \\
\hline LOC111889458 & GO:0004865 & Protein phosphatase inhibitor activity \\
\hline LOC111889458 & GO:0032516 & Negative regulation of phosphoprotein phosphatase activity \\
\hline LOC111889458 & GO:0005738 & Cytoplasm \\
\hline LOC111889458 & GO:0005887 & Plasma membrane \\
\hline LOC111889538 & GO:0003825 & Catalytic activity \\
\hline
\end{tabular}


Supplemental Table 2. (Continued)

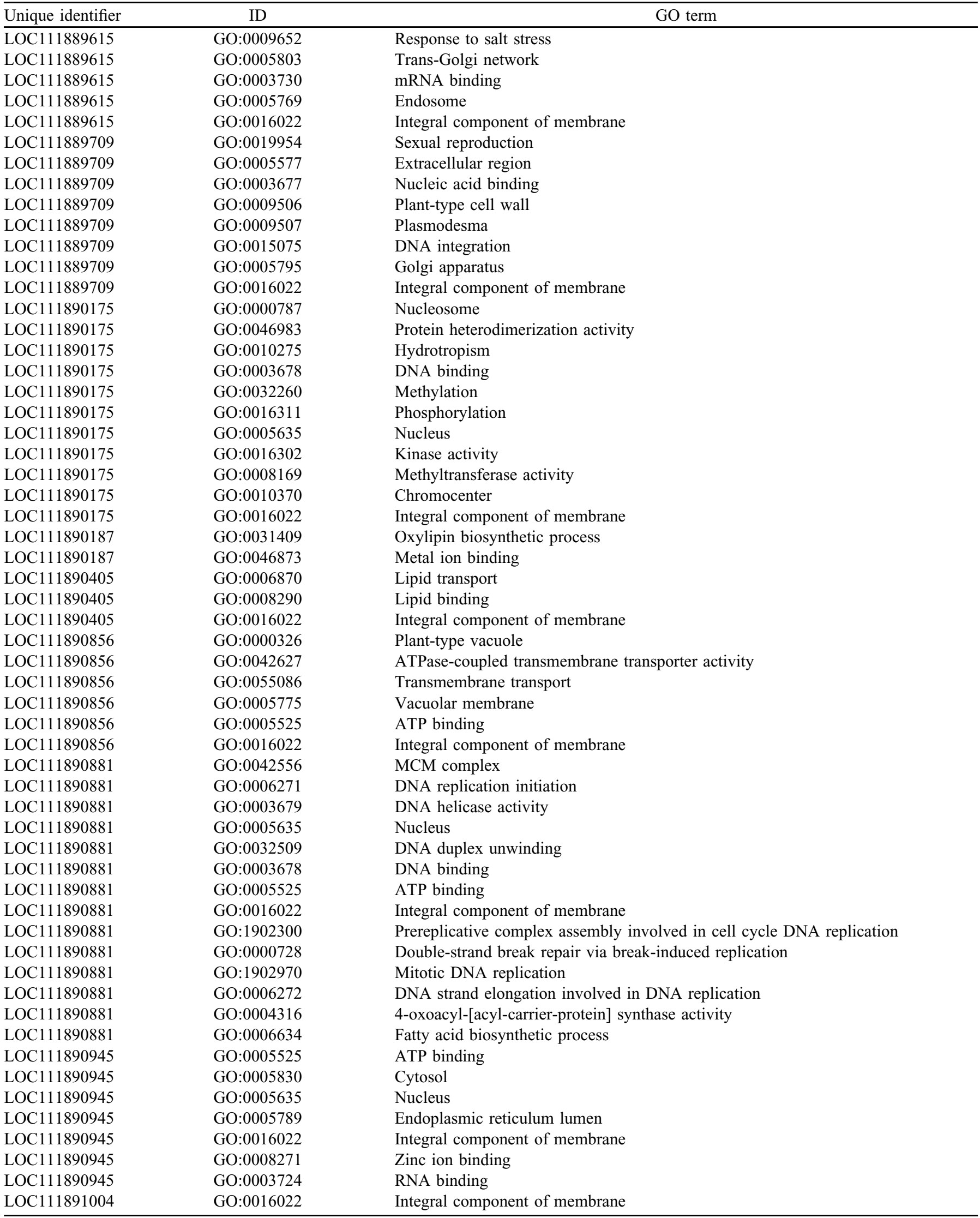


Supplemental Table 2. (Continued)

\begin{tabular}{|c|c|c|}
\hline Unique identifier & ID & GO term \\
\hline LOC111891022 & GO:0030247 & Carbohydrate binding \\
\hline LOC111891176 & GO:0033898 & Ribonuclease T2 activity \\
\hline LOC111891176 & GO:0090503 & RNA phosphodiester bond hydrolysis, endonucleolytic \\
\hline LOC111891176 & GO:0071945 & Cell periphery \\
\hline LOC111891176 & GO:0016021 & Membrane \\
\hline LOC111891176 & GO:0016830 & Lyase activity \\
\hline LOC111891176 & GO:0003724 & RNA binding \\
\hline LOC111891176 & GO:0009719 & Anthocyanin-containing compound biosynthetic process \\
\hline LOC111891176 & GO:0016037 & Cellular response to phosphate starvation \\
\hline LOC111891176 & GO:0009612 & Response to wounding \\
\hline LOC111891176 & GO:0009868 & Jasmonic acid-mediated signaling pathway \\
\hline LOC111891274 & GO:0006818 & Phosphate ion transport \\
\hline LOC111891274 & GO:0006858 & Oligopeptide transport \\
\hline LOC111891274 & GO:0015707 & Nitrate transport \\
\hline LOC111891274 & GO:0010168 & Response to nitrate \\
\hline LOC111891617 & GO:0015268 & Channel activity \\
\hline LOC111891617 & GO:0006834 & Water transport \\
\hline LOC111891617 & GO:0016022 & Integral component of membrane \\
\hline LOC111891617 & GO:0055086 & Transmembrane transport \\
\hline LOC111891617 & GO:0005373 & Water transmembrane transporter activity \\
\hline LOC111891617 & GO:0005775 & Vacuolar membrane \\
\hline LOC111891617 & GO:0000327 & Protein storage vacuole \\
\hline LOC111891670 & GO:0004673 & Protein kinase activity \\
\hline LOC111892092 & GO:0016022 & Integral component of membrane \\
\hline LOC111892092 & GO:0019749 & Secondary metabolic process \\
\hline LOC111892092 & GO:0016748 & Transferase activity, transferring acyl groups other than amino-acyl groups \\
\hline LOC111892644 & GO:0016302 & Kinase activity \\
\hline LOC111892644 & GO:0006469 & Protein phosphorylation \\
\hline LOC111892644 & GO:0005887 & Plasma membrane \\
\hline LOC111892644 & GO:0016774 & Phosphotransferase activity, alcohol group as acceptor \\
\hline LOC111892644 & GO:0140097 & Catalytic activity, acting on a protein \\
\hline LOC111892644 & GO:0005525 & ATP binding \\
\hline LOC111892644 & GO:0042743 & Defense response to bacterium \\
\hline LOC111892644 & GO:0005516 & Protein binding \\
\hline LOC111893009 & GO:0004479 & Methionine adenosyltransferase activity \\
\hline LOC111893009 & GO:0006557 & S-adenosylmethionine biosynthetic process \\
\hline LOC111893009 & GO:0005738 & Cytoplasm \\
\hline LOC111893009 & GO:0006731 & One-carbon metabolic process \\
\hline LOC111893009 & GO:0005525 & ATP binding \\
\hline LOC111893009 & GO:0009507 & Plasmodesma \\
\hline LOC111893009 & GO:0005635 & Nucleus \\
\hline LOC111893009 & GO:0046873 & Metal ion binding \\
\hline
\end{tabular}


Supplemental Table 2. (Continued)

\begin{tabular}{|c|c|c|}
\hline Unique identifier & ID & GO term \\
\hline$\overline{\text { LOC111893009 }}$ & GO:0005887 & Plasma membrane \\
\hline LOC111893009 & GO:0009861 & Pollen tube growth \\
\hline LOC111893009 & GO:0012506 & Endomembrane system \\
\hline LOC111893009 & GO:0005516 & Protein binding \\
\hline LOC111893009 & GO:0009810 & Lignin biosynthetic process \\
\hline LOC111893042 & GO:0015268 & Channel activity \\
\hline LOC111893042 & GO:0016022 & Integral component of membrane \\
\hline LOC111893042 & GO:0006834 & Water transport \\
\hline LOC111893042 & GO:0005373 & Water transmembrane transporter activity \\
\hline LOC111893042 & GO:0045491 & Pectin catabolic process \\
\hline LOC111893042 & GO:0030600 & Pectinesterase activity \\
\hline LOC111893157 & GO:0004436 & Phosphatidylinositol phospholipase $\mathrm{C}$ activity \\
\hline LOC111893157 & GO:0003678 & DNA binding \\
\hline LOC111893157 & GO:0042824 & Pyridoxal phosphate biosynthetic process \\
\hline LOC111893158 & GO:0004436 & Phosphatidylinositol phospholipase $\mathrm{C}$ activity \\
\hline LOC111893158 & GO:0016043 & Lipid catabolic process \\
\hline LOC111893158 & GO:0005887 & Plasma membrane \\
\hline LOC111893158 & GO:0035557 & Intracellular signal transduction \\
\hline LOC111893158 & GO:0005510 & Calcium ion binding \\
\hline LOC111893158 & GO:0005526 & GTP binding \\
\hline LOC111893158 & GO:0042255 & Ribosome biogenesis \\
\hline LOC111893574 & GO:0016022 & Integral component of membrane \\
\hline LOC111893605 & GO:0003701 & DNA-binding transcription factor activity \\
\hline LOC111893605 & GO:0000166 & MAPK cascade \\
\hline LOC111893678 & GO:0043532 & ADP binding \\
\hline LOC111893678 & GO:0006953 & Defense response \\
\hline LOC111893678 & GO:0016022 & Integral component of membrane \\
\hline LOC111893678 & GO:0006509 & Proteolysis \\
\hline LOC111893678 & GO:0008235 & Cysteine-type peptidase activity \\
\hline LOC111893678 & GO:0005525 & ATP binding \\
\hline LOC111893963 & GO:0008644 & Carbohydrate transport \\
\hline LOC111893963 & GO:0051120 & Sugar transmembrane transporter activity \\
\hline LOC111893963 & GO:0005887 & Plasma membrane \\
\hline LOC111893963 & GO:0016022 & Integral component of membrane \\
\hline LOC111893963 & GO:0008516 & Sucrose transmembrane transporter activity \\
\hline LOC111893963 & GO:0098657 & Anion transmembrane transport \\
\hline LOC111894108 & GO:0045549 & Phenylalanine ammonia-lyase activity \\
\hline LOC111894108 & GO:0009801 & Cinnamic acid biosynthetic process \\
\hline LOC111894108 & GO:0005738 & Cytoplasm \\
\hline LOC111894108 & GO:0032992 & Protein-containing complex \\
\hline LOC111894108 & GO:0016598 & Amino acid binding \\
\hline LOC111894108 & GO:1902223 & Erythrose 4-phosphate/phosphoenolpyruvate family amino acid catabolic process \\
\hline LOC 111894108 & GO:0006559 & L-phenylalanine metabolic process \\
\hline
\end{tabular}

(Continued on next page) 
Supplemental Table 2. (Continued)

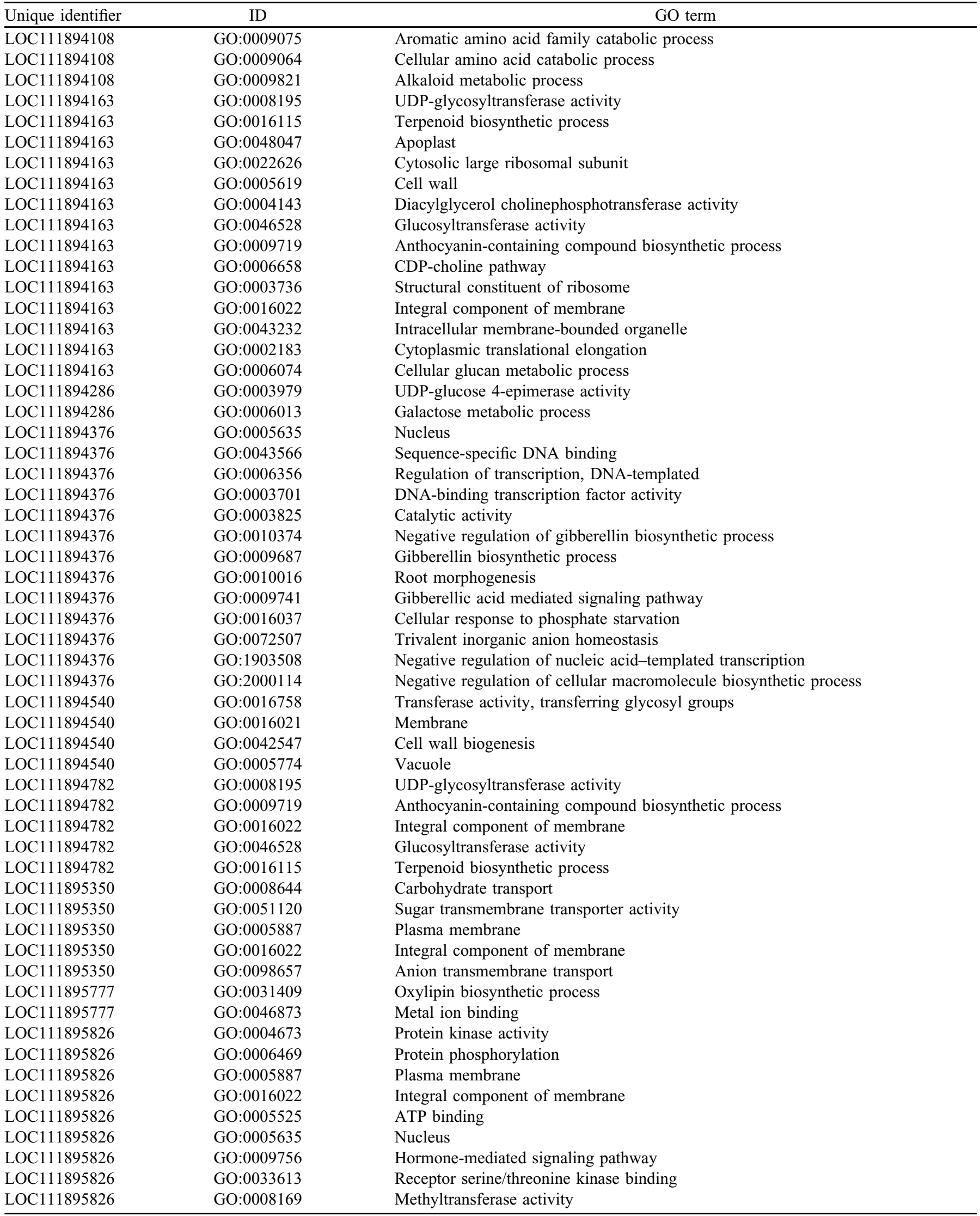


Supplemental Table 2. (Continued)

\begin{tabular}{lll}
\hline Unique identifier & \multicolumn{1}{c}{ ID } & \multicolumn{1}{c}{ GO term } \\
\hline LOC111895826 & GO:0046874 & Metal ion transmembrane transporter activity \\
LOC111895826 & GO:0006398 & mRNA processing \\
LOC111895826 & GO:0032260 & Methylation \\
LOC111895826 & GO:0030002 & Metal ion transport \\
LOC111895938 & GO:0005577 & Extracellular region \\
LOC111895938 & GO:0019954 & Sexual reproduction \\
LOC111895938 & GO:0016022 & Integral component of membrane \\
LOC111896413 & GO:0006980 & Response to oxidative stress \\
\hline
\end{tabular}

Supplemental Table 3. List of genes determined to be differentially expressed from RNA sequencing analyses between lettuce grown unshaded (control) or shaded and their putative functions as annotated in the National Center for Biotechnology Information database. $\log _{2} \mathrm{FC}=\log$-fold change $>2$ of unshaded control lettuce relative to the shaded lettuce; genes with positive $\log _{2} \mathrm{FC}$ were expressed to a greater degree in control than shaded lettuce. All gene functions were identified for Lactuca sativa.

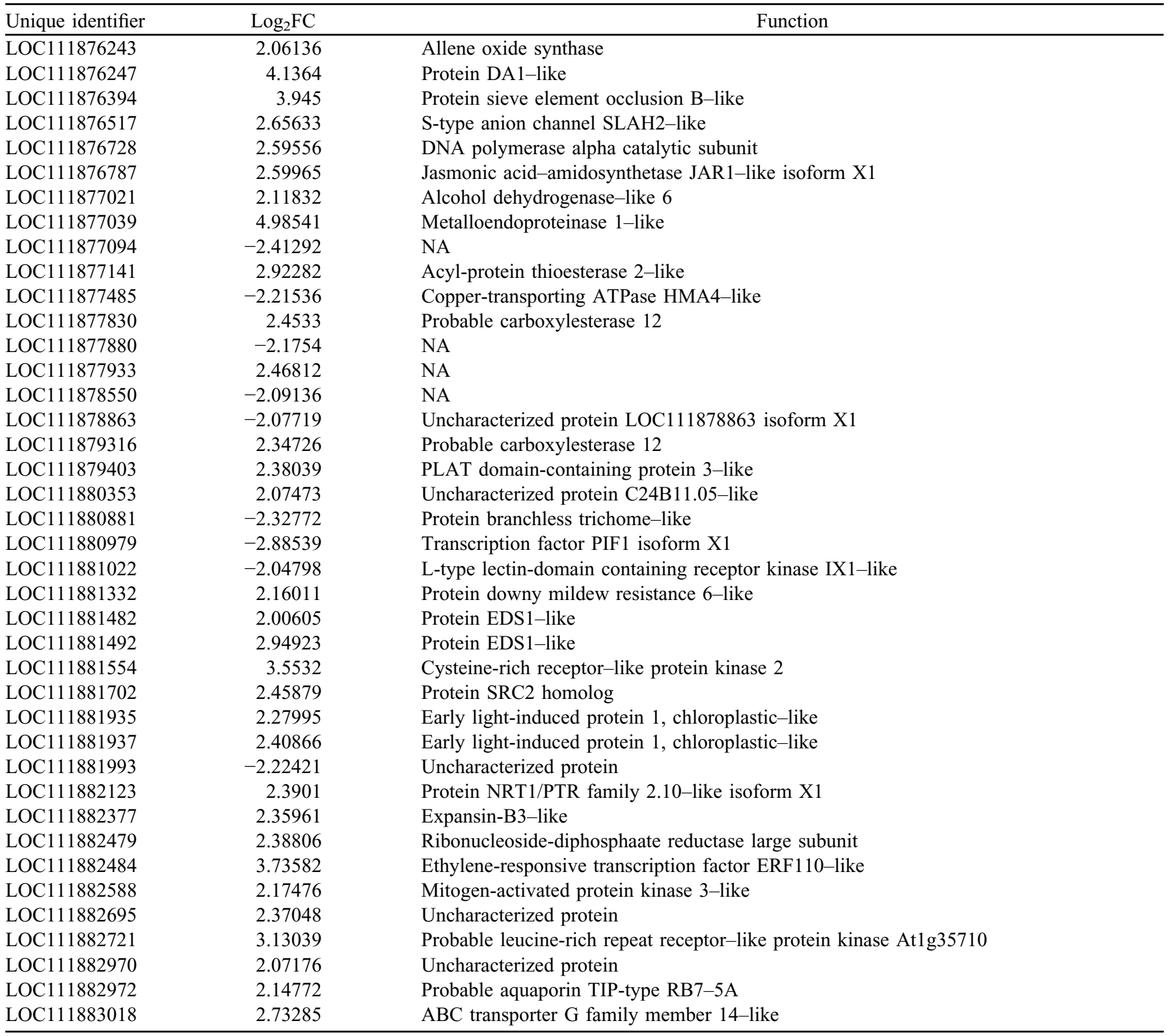


Supplemental Table 3. (Continued)

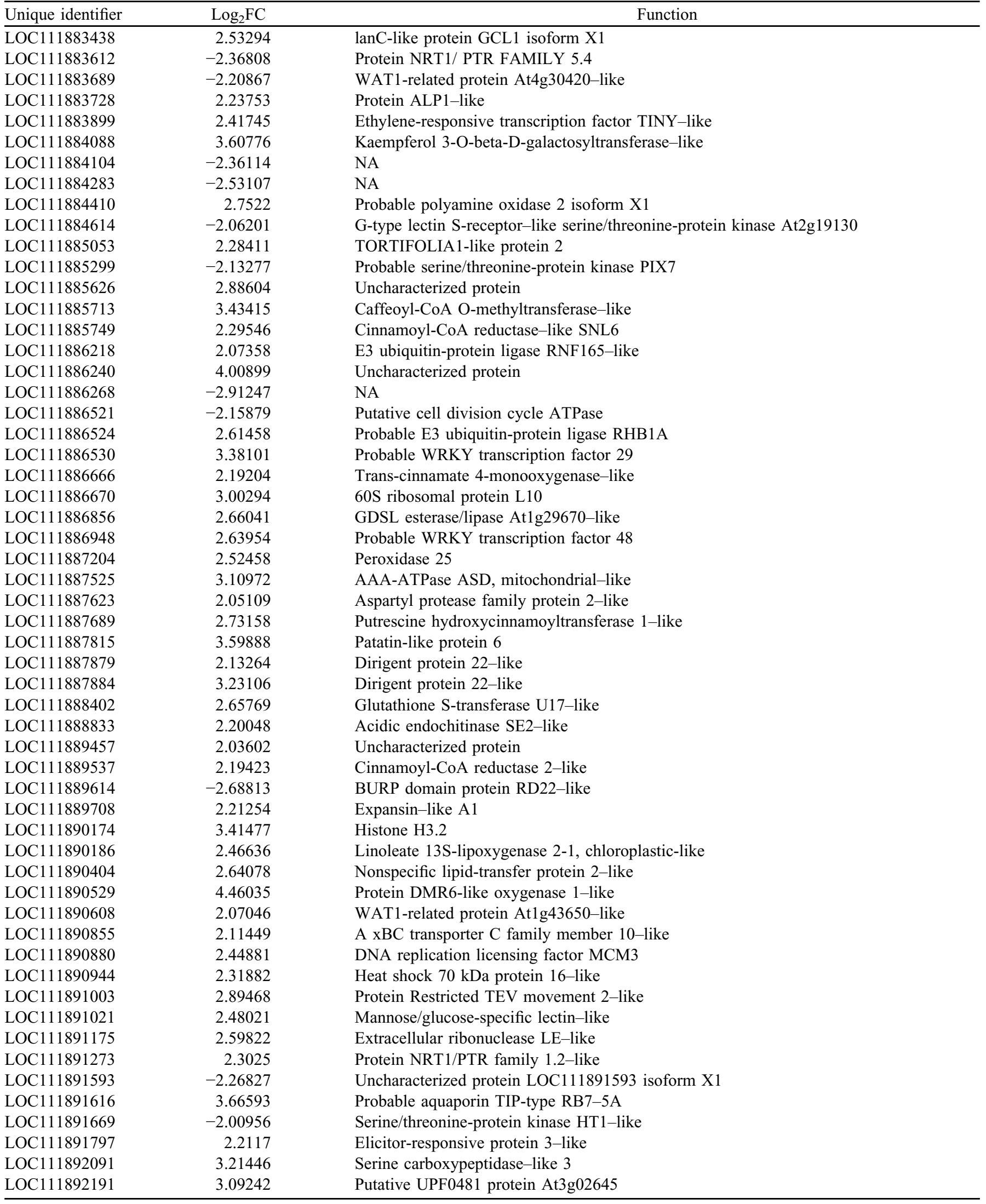


Supplemental Table 3. (Continued)

\begin{tabular}{|c|c|c|}
\hline Unique identifier & $\log _{2} \mathrm{FC}$ & Function \\
\hline LOC111892407 & 2.22091 & F-box protein SKIP27-like \\
\hline LOC111892511 & 2.13289 & Artemisinic aldehyde Delta(11(13)) reductase \\
\hline LOC111892643 & 2.47764 & Serine/threonine-protein kinase RIPK-like \\
\hline LOC111893041 & -3.82352 & Aquaporin TIP1-1-like \\
\hline LOC111893156 & 2.656 & Phosphoinositide phospholipase C 4-like \\
\hline LOC111893157 & 2.89318 & Phosphoinositide phospholipase C 2-like \\
\hline LOC111893573 & -2.65074 & F-box protein At2g27310-like \\
\hline LOC111893604 & 2.01957 & bZIP transcription factor 11-like \\
\hline LOC111893677 & 2.5044 & Putative disease resistance RPP12-like protein 2 \\
\hline LOC111893685 & 2.24254 & Uncharacterized protein LOC111893685 isoform X1 \\
\hline LOC111893884 & -2.10778 & NA \\
\hline LOC111893962 & 2.06514 & Bidirectional sugar transporter SWEET14-like \\
\hline LOC111894539 & 2.3947 & Galactan beta-1,4-galactosyltransferase GALS3-like \\
\hline LOC111894781 & 2.83561 & Kaempferol 3-O-beta-D-galactosyltransferase-like \\
\hline LOC111895349 & 2.49039 & Bidirectional sugar transporter SWEET14-like \\
\hline LOC111895541 & -2.01298 & NA \\
\hline LOC111895744 & 2.16822 & Organ-specific protein S2-like \\
\hline LOC111895776 & 2.6741 & Probable linoleate 9S-lipoxygenase \\
\hline LOC111895825 & 2.45401 & Probable leucine-rich repeat receptor-like protein kinase At1g35710 \\
\hline LOC111895937 & -2.01183 & Expansin-like B1 \\
\hline LOC111896412 & 2.88668 & Peroxidase N1-like \\
\hline LOC111896417 & 2.45955 & Transcription factor MYB61-like \\
\hline LOC111896675 & 2.85416 & Uncharacterized protein \\
\hline LOC111898223 & 2.58181 & Protein LURP-one-related 10-like \\
\hline LOC111898297 & 2.19462 & Inositol-tetrakisphosphate 1-kinase 5-like \\
\hline LOC111898348 & 2.51157 & Uncharacterized protein \\
\hline LOC111898411 & -2.88755 & Auxin-responsive protein IAA29-like \\
\hline LOC111898507 & 2.59846 & Isoflavone reductase homolog \\
\hline LOC111898508 & 2.19367 & UDP-glucosyl transferase 73B2-like \\
\hline LOC111898605 & 2.02453 & NA \\
\hline LOC111898611 & 2.84834 & ruBisCO large subunit-binding protein subunit beta, chloroplastic-like \\
\hline LOC111898626 & 3.4482 & UDP-glycosyltransferase 74G1-like \\
\hline LOC111898732 & 2.87366 & $\mathrm{BTB} / \mathrm{POZ}$ and TAZ domain-containing protein 1-like \\
\hline LOC111899032 & 2.46596 & Metacaspase-1-like \\
\hline LOC111899252 & 2.56638 & Beta-caryophyllene synthase-like \\
\hline LOC111899324 & 2.45384 & Probable trehalose-phosphatase D \\
\hline LOC111899382 & 2.21906 & Glucan endo-1,3-beta-glucosidase, acidic-like \\
\hline LOC111899637 & 2.26143 & Uncharacterized protein \\
\hline LOC111899806 & 2.11987 & Fasciclin-like arabinogalactan protein 17 \\
\hline LOC111900009 & -2.11973 & Monothiol glutaredoxin-S4-like \\
\hline LOC111900059 & 2.49352 & Probable carboxylesterase 17 \\
\hline LOC111900135 & -2.0976 & Uncharacterized protein \\
\hline LOC111900177 & 2.12291 & Patatin-like protein 7 \\
\hline
\end{tabular}


Supplemental Table 3. (Continued)

\begin{tabular}{|c|c|c|}
\hline Unique identifier & $\log _{2} \mathrm{FC}$ & Function \\
\hline LOC111900246 & 4.43221 & Ribulose bisphosphate carboxylase small chain 4 , chloroplastic-like \\
\hline LOC111900788 & 2.98652 & Arabinogalactan peptide 13 -like \\
\hline LOC111900976 & 2.55533 & Serine carboxypeptidase-like \\
\hline LOC111901004 & 2.18256 & S-linalool synthase \\
\hline LOC111901011 & 2.75193 & Chitin-inducible gibberellin-responsive protein 1-like \\
\hline LOC111901413 & -2.39575 & NA \\
\hline LOC111901426 & 2.26332 & Arogenate dehydratase/prephenate dehydratase 6 , chloroplastic-like \\
\hline LOC111901609 & 2.20249 & Uncharacterized protein \\
\hline LOC111901674 & -2.22187 & NA \\
\hline LOC111901838 & 2.35442 & Uncharacterized protein \\
\hline LOC111902855 & 4.18664 & Glycine-rich protein DC7.1-like \\
\hline LOC111903004 & 2.7961 & Caffeic acid 3-O-methyltransferase-like \\
\hline LOC111903226 & 2.61053 & Protein detoxification $49-$ like \\
\hline LOC111903232 & 2.54125 & Ethylene-responsive transcription factor ERF027-like \\
\hline LOC111903507 & 2.42471 & Desumoylating isopeptidase $1-$ like \\
\hline LOC111903572 & 2.24376 & R-linalool synthase QH1, chloroplastic-like \\
\hline LOC111903849 & 2.06014 & AP2-like ethylene-responsive transcription factor AIL 1 \\
\hline LOC111903871 & -2.00381 & Serine/threonine-protein kinase STY46-like \\
\hline LOC111904177 & -2.1879 & $\begin{array}{l}\text { Receptor homology region, transmembrane domain- and } \\
\text { RING domain-containing protein } 2 \text {-like }\end{array}$ \\
\hline LOC111904236 & 3.36666 & Serine carboxypeptidase-like 13 \\
\hline LOC111905399 & 4.22205 & Cytochrome P450 94C1 \\
\hline LOC111905890 & 3.29579 & Auxin response factor 16 -like \\
\hline LOC111906005 & 2.44252 & Benzoate carboxyl methyltransferase-like \\
\hline LOC111906255 & 2.12874 & probable aquaporin PIP2-5 \\
\hline LOC111906468 & 2.40144 & Mitochondrial phosphate carrier protein 3, mitochondrial-like \\
\hline LOC111906534 & 2.68468 & Probable glutathione S-transferase parA \\
\hline LOC111906761 & 3.13159 & Probable anion transporter 3 , chloroplastic \\
\hline LOC111906858 & 2.37683 & Inorganic pyrophosphatase 2 -like \\
\hline LOC111906884 & -2.43753 & NA \\
\hline LOC111907185 & 2.77558 & Late embryogenesis abundant protein -like \\
\hline LOC111907568 & 2.23141 & Amino-acid permease BAT1 homolog isoform X1 \\
\hline LOC111907636 & 2.40167 & Peptidyl-prolyl cis-trans isomerase FKBP62-like \\
\hline LOC111907716 & 3.99943 & Ssteroid 5-alpha-reductase DET2-like \\
\hline LOC111907787 & -2.30506 & Auxin-responsive protein SAUR71-like \\
\hline LOC111907847 & 3.10352 & Protein detoxification 40 -like \\
\hline LOC111907858 & 2.05972 & 5'-adenylylsulfate reductase 3 , chloroplastic-like \\
\hline LOC111907932 & 2.74001 & ABC transporter $\mathrm{G}$ family member 29 -like \\
\hline LOC111907938 & -2.19636 & FK506-binding protein 5-like \\
\hline LOC111908023 & 2.9191 & Probable boron transporter 6 \\
\hline LOC111908115 & 2.55272 & Protein proton gradient regulation 5 , chloroplastic-like \\
\hline
\end{tabular}


Supplemental Table 3. (Continued)

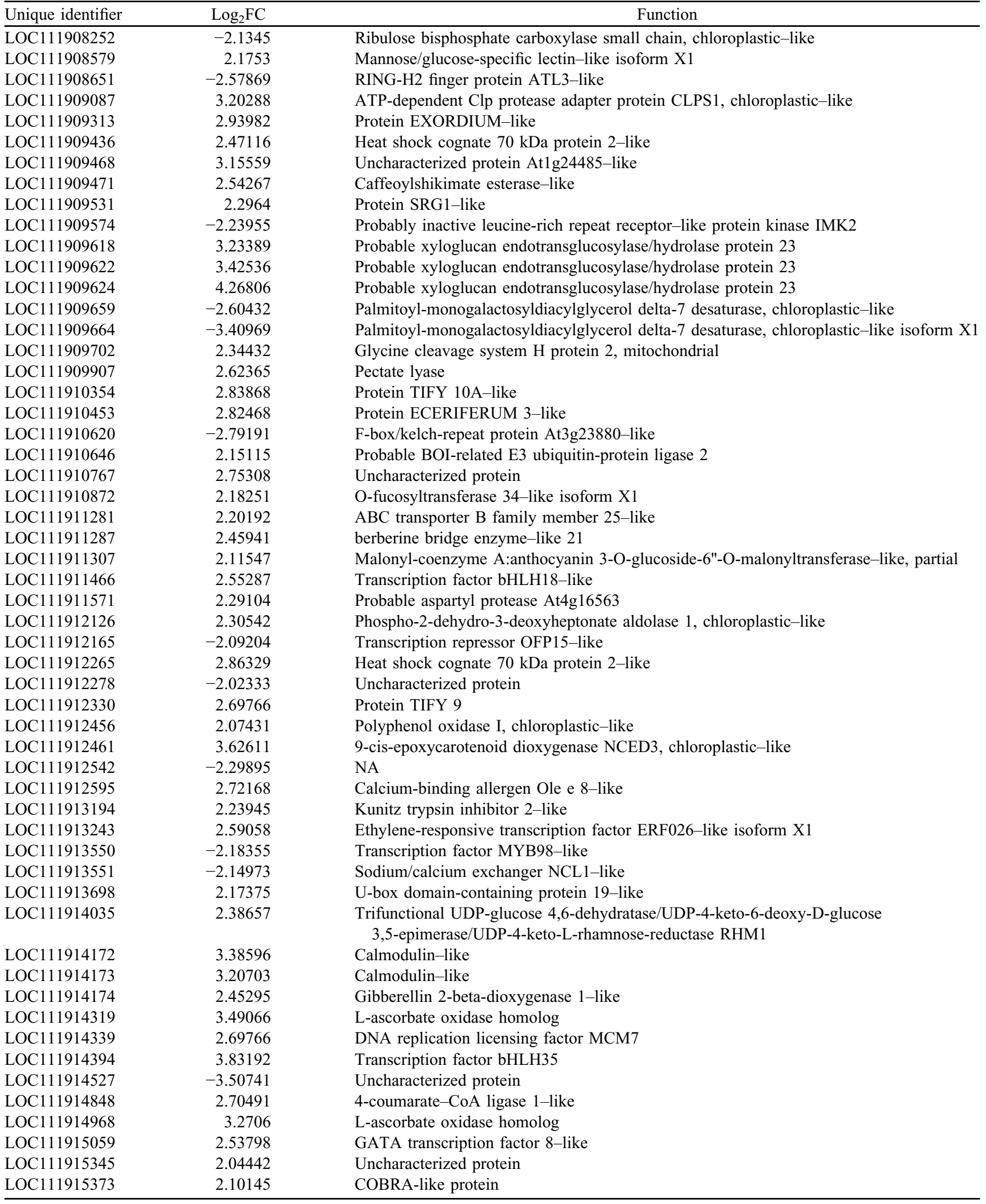


Supplemental Table 3. (Continued)

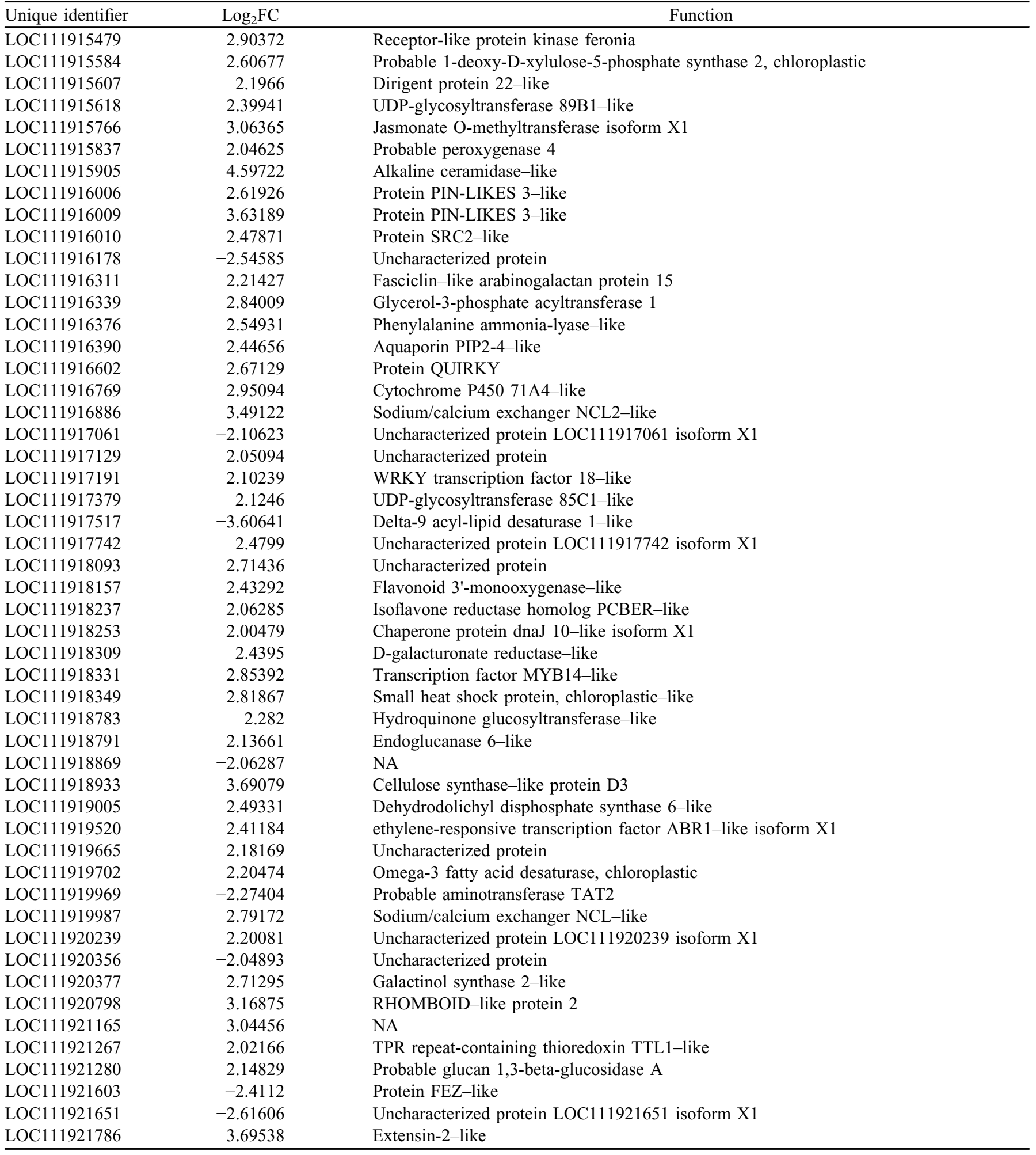

